\title{
Moment-Curvature Behaviors of Concrete Beams Singly Reinforced by Steel-FRP Composite Bars
}

\author{
Zeyang Sun, ${ }^{1,2}$ Yang Yang, ${ }^{2,3}$ Wenlong Yan, ${ }^{1,2}$ Gang Wu, ${ }^{1}$ and Xiaoyuan $\mathrm{He}^{2}$ \\ ${ }^{1}$ Southeast University, Key Laboratory of Concrete and Prestressed Concrete Structures of the Ministry of Education, \\ Nanjing 210096, China \\ ${ }^{2}$ School of Civil Engineering, Southeast University, Nanjing 210096, China \\ ${ }^{3}$ College of Civil Science and Engineering, Yangzhou University, Jiangsu 225127, China
}

Correspondence should be addressed to Gang Wu; g.wu@seu.edu.cn

Received 6 October 2016; Revised 4 December 2016; Accepted 26 December 2016; Published 15 February 2017

Academic Editor: John Mander

Copyright (C) 2017 Zeyang Sun et al. This is an open access article distributed under the Creative Commons Attribution License, which permits unrestricted use, distribution, and reproduction in any medium, provided the original work is properly cited.

A steel-fiber-reinforced polymer (FRP) composite bar (SFCB) is a kind of rebar with inner steel bar wrapped by FRP, which can achieve a better anticorrosion performance than that of ordinary steel bar. The high ultimate strength of FRP can also provide a significant increase in load bearing capacity. Based on the adequate simulation of the load-displacement behaviors of concrete beams reinforced by SFCBs, a parametric analysis of the moment-curvature behaviors of concrete beams that are singly reinforced by SFCB was conducted. The critical reinforcement ratio for differentiating the beam's failure mode was presented, and the concept of the maximum possible peak curvature (MPPC) was proposed. After the ultimate curvature reached MPPC, it decreased with an increase in the postyield stiffness ratio $\left(r_{\mathrm{sf}}\right)$, and the theoretical calculation method about the curvatures before and after the MPPC was derived. The influence of the reinforcement ratio, effective depth, and FRP ultimate strain on the ultimate point was studied by the dimensionless moment and curvature. By calculating the envelope area under the moment-curvature curve, the energy ductility index can obtain a balance between the bearing capacity and the deformation ability. This paper can provide a reference for the design of concrete beams that are reinforced by SFCB or hybrid steel bar/FRP bar.

\section{Introduction}

The corrosion of steel bars in concrete structures will demolish the bonding performance and lead to the cracks of concrete due to the volume expansion of corrosion products [1]. Fiber-reinforced polymer (FRP) is a type of composite with superior anticorrosion performance in concrete structures $[2,3]$; the successive research and application of glass FRP (GFRP) for the repair of bridges and parking lots prompted the Canadian government to reexamine this type of material to extend the service life of concrete structures. Experimental and theoretical studies on concrete beams that are reinforced by GFRP were conducted by Benmokrane et al. (1996) [4], and the results of these studies indicated that the calculation method of the bearing capacity and the displacement of the American Concrete Institute (ACI) code [5] can be employed for a GFRP beam with minor modifications. For concrete bridges or marine structures in Canada, a GFRP-reinforced structure can maintain superior performance (Mufti et al., 2007) [6]; the adhesions between GFRP and concrete were undamaged in 5 8 years, and the alkaline substance did not penetrate the GFRP reinforcement. The Canadian Highway Bridge Design Code [7] has enabled designers to use GFRP bars as a primary means of reinforcement in concrete structures, but for a prestressed concrete structure, the GFRP bar's service strength is limited to $25 \%$ of its ultimate strength due to its elastic property (brittle failure), and, according to ACI 440.4R-04 [8], GFRPs are not allowed for prestressing application because of their weak creep-rupture characteristics.

To improve the performance of an FRP-reinforced concrete structure, a hybrid FRP bar with different ultimate strains was proposed [9] to achieve a certain degree of ductility, but this type of ductility was realized by the partial rupture of FRP with a low elongation rate, which will exhibit significant strength degradation during cyclic loading. Because a steel bar has a large elongation rate (approximately $15 \%$ ), 
a better performance and a more acceptable cost can be achieved by combining steel and FRP. Two combinations exist: (1) a concrete beam hybrid reinforced by steel bars and FRP bars; (2) beams reinforced by steel-FRP composite bars. Twelve concrete beams that were reinforced by a steel bar, a GFRP bar, or a steel/GFRP bar were tested by Lau and Pam (2010) [10]; the results indicated that the ductility of hybrid reinforced beams was better than the ductility of a pure FRPreinforced beam; the minimum reinforcement ratio for an FRP-reinforced beam could be reduced by $25 \%$ according to the ACI 440.1R-06 [11]. A study of twelve concrete beams, which were reinforced by steel bar and GFRP bar, was conducted by Safan (2013) [12], and the results showed that the failure modes of concrete beams were presented as concrete crushing after the yielding of the steel bar on the tensile side and a GFRP bar can maintain the flexural bearing capacity of a concrete beam with a relatively small reinforcement ratio. A ductility index was proposed by Pang et al. (2015) [13] to evaluate the load-displacement relationship of a hybrid reinforced concrete beam and the corresponding method of differentiation of the failure mode was suggested, but this method of differentiation was slightly complicated. An experimental study on six hybrid reinforced concrete beams was conducted by El Refai et al. (2015) [14], and the results indicated that the deflection of the hybrid reinforcement beam with the higher reinforcement ratio can be well predicted by current design codes; the crack width was calculated by ACI-440.1R-06 [11] by modifying the bonding coefficient between the FRP bar and concrete.

Deterioration failure can occur in concrete beams that are reinforced by hybrid steel bars/FRP bars when a steel bar is subjected to corrosion. A better anticorrosion performance can be achieved by a steel-FRP composite bar (SFCB), which is a type of rebar with an inner steel bar and an outer FRP. Sixteen concrete beams reinforced by hybrid rebar were tested by Nanni et al. (1994) [15], and the theoretical analysis of the load-displacement curves revealed that the calculated displacement was slightly smaller than that of the test curves when the slip between the FRP and concrete was disregarded, and the load-carrying capacity of the hybrid reinforced beams can be calculated using traditional RC theory. Concrete beams that are reinforced by longitudinal steel-GFRP composite bars and GFRP stirrups were tested by Saikia et al. (2005) [16]; the composite bar was composed of an inner steel bar with a diameter of $6 \mathrm{~mm}$ that is helically wounded by GFRP with a thickness of $2 \mathrm{~mm}$. Due to an underdeveloped manufacturing technology, a slip between the inner steel bar and the outer GFRP occurred. A factory-produced SFCB was achieved by $\mathrm{Wu}$ et al. by modifying the pultrusion process of FRP bars [17], and its characteristics include the following: (1) the initial elastic modulus and the postyield modulus can be designed by adjusting the steel/FRP ratio; (2) a durability of SFCB that is equivalent to the durability of FRP bar can be achieved (Figure 1(a) [18]); (3) the strength of the inner steel bar can be effectively employed, and the high ultimate strength of FRP can be employed as a reservation; (4) the performance/cost ratio of a concrete structure reinforced by steel-FRP composite bars can be optimized with considering the long-term performance and bearing capacity. The typical

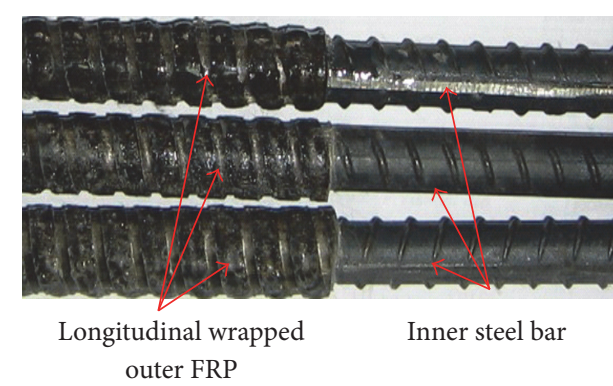

(a) Steel-FRP composite bars

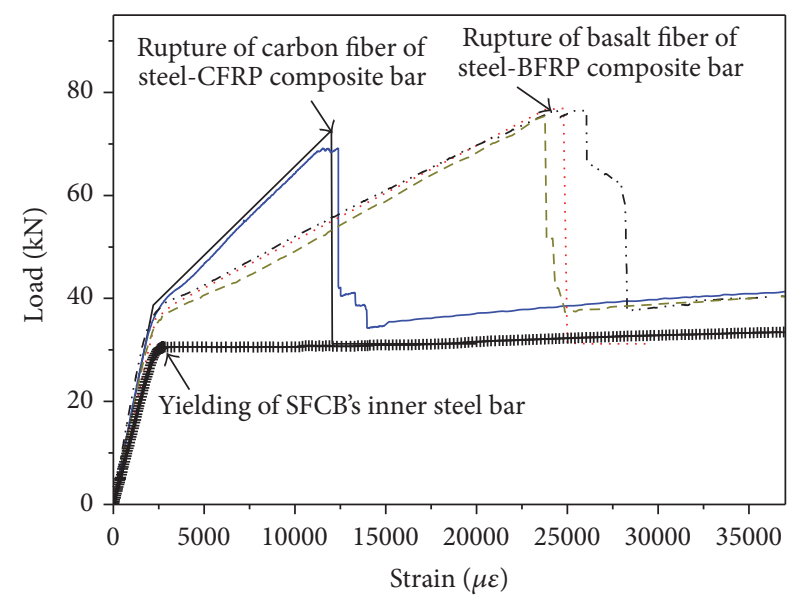

(b) Load-strain curves

FIGURE 1: Factory production of SFCB and its mechanical properties.

load-strain curves of steel-basalt FRP composite bars and steel-carbon FRP composite bars are illustrated in Figure 1(b), and the stress-strain model of SFCB has been comprehensively investigated [19]. It was demonstrated that there was no slip between the inner steel and outer FRP during the loading process. An experimental study of a concrete beam that is reinforced with SFCBs, steel bars, and pure FRP bars under static loading was conducted by the author's group [20], and research on the effect of blast load [21] is to be conducted. In this paper, a parametric analysis of the moment-curvature behavior is conducted based on the simulation of the loaddisplacement curve of an SFCB-reinforced concrete beam; the corresponding curvature ductility index is also discussed. The research results of this paper can provide a reference for the design of hybrid reinforced concrete beams.

\section{Simulation of a Concrete Beam Reinforced by SFCB}

2.1. Material Parameters. Experimental studies of six concrete beams were conducted by Sun et al. (2012) [20], and the SFCB beams exhibit a stable postyield stiffness after the yielding of SFCB's inner steel bar, and concrete crushed after the rupture of SFCB's outer FRP. The conventional RC beam had the largest ductility, whereas the ultimate load of the RC beam was approximately $31 \%$ of the ultimate load of the SFCB beam. To calculate the moment-curvature behavior of the 


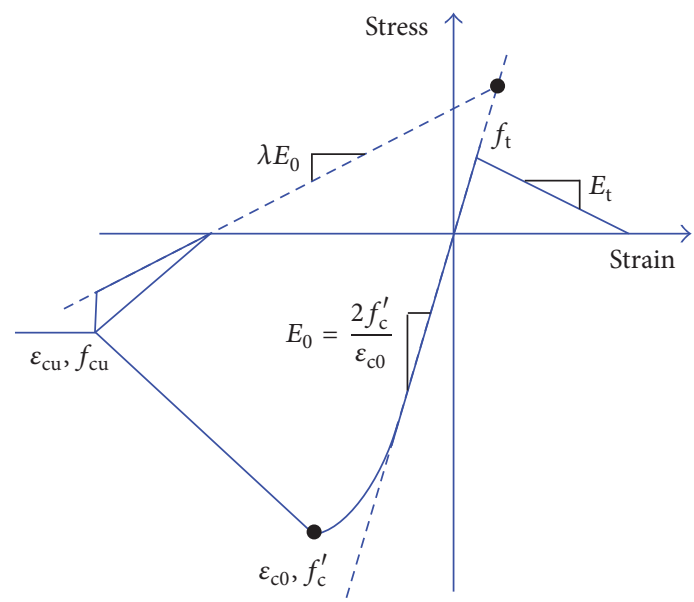

FIGURE 2: Stress-strain behavior of the concrete model.

concrete beam that is reinforced by SFCB, the comparison analysis between the experimental results of the SFCB beam and the calculated curves are conducted. Concrete02 in OpenSees (OS) [22] is adopted for concrete stress-strain behavior (Figure 2). The peak stress and strain of concrete can be expressed by (1) and (2) [23], and the relationship between the crush strain and the volumetric percentage of stirrups is shown in (3):

$$
\begin{aligned}
& f_{\mathrm{c} 0}=K f_{\mathrm{c}}^{\prime}=\left(1+\frac{\rho_{\mathrm{sv}} f_{\mathrm{yh}}}{f_{\mathrm{c}}^{\prime}}\right) f_{\mathrm{c}}^{\prime}, \\
& \varepsilon_{\mathrm{c} 0}=0.002 K=0.002\left(1+\frac{\rho_{\mathrm{sv}} f_{\mathrm{yh}}}{f_{\mathrm{c}}^{\prime}}\right), \\
& \varepsilon_{\mathrm{cu}}=0.004+\frac{\rho_{\mathrm{sv}} f_{\mathrm{yh}}[\mathrm{MPa}]}{300},
\end{aligned}
$$

where $f_{\mathrm{c}}^{\prime}$ and $\varepsilon_{\mathrm{c} 0}$ are the peak stress and peak strain, respectively; $\varepsilon_{\mathrm{cu}}$ is the ultimate compressive strain of concrete; $\rho_{\mathrm{sv}}$ is the volumetric percentage of the stirrups; and $f_{\mathrm{yh}}$ is the yield strength of the stirrups.

The load-strain relationship of a SFCB is a trilinear model (Figure 1(b)), where the rupture of SFCB's outer FRP is defined as the failure point. As a result, the trilinear model can be simplified in two stages (see (4)). The first stage is before yielding $\left(E_{\mathrm{I}}\right)$, and the second stage is between yielding and FRP rupture $\left(E_{\mathrm{II}}\right)$.

$$
f_{\text {sf }}= \begin{cases}E_{\mathrm{I}} \varepsilon_{\mathrm{sf}} & \left(0 \leq \varepsilon_{\mathrm{sf}} \leq \varepsilon_{\mathrm{sfy}}\right) \\ f_{\mathrm{sfy}}+E_{\mathrm{II}}\left(\varepsilon_{\mathrm{sf}}-\varepsilon_{\mathrm{sfy}}\right) & \left(\varepsilon_{\mathrm{sfy}} \leq \varepsilon_{\mathrm{sf}} \leq \varepsilon_{\mathrm{sfu}}\right)\end{cases}
$$

where $f_{\text {sf }}$ and $\varepsilon_{\text {sf }}$ are the stress of SFCB and the strain of SFCB, respectively; $E_{\mathrm{I}}$ is the elastic modulus before yielding; $E_{\mathrm{II}}$ is the postyield modulus of SFCB; $f_{\text {sfy }}$ and $\varepsilon_{\text {sfy }}$ are the yield stress of SFCB and the yield strain of SFCB, respectively; and $f_{\text {sfu }}$ and $\varepsilon_{\text {sfu }}$ are the ultimate stress and the ultimate strain of $\mathrm{SFCB}$ at the point of FRP rupture, respectively.
The mechanical behavior of SFCBs in OS is realized by established separate fibers of steel and FRP. For steel fiber, the key points are the yield point, the hardening point, the hardening slope, and the ultimate point, which can be described by the Chang and Mander (1994) model [24]. For FRP, a linear elastic element is defined to represent the elastic behavior. The postyield stiffness ratio $r_{\text {sf }}$ of an SFCB can be defined by (5), and the corresponding equivalent longitudinal reinforcement ratio $\left(\rho_{\mathrm{sf}}^{\mathrm{e}}\right)$ with regard to conventional steel reinforced concrete beam is defined by (6):

$$
\begin{aligned}
r_{\mathrm{sf}} & =\frac{E_{\mathrm{f}} A_{\mathrm{f}}}{\left(E_{\mathrm{s}} A_{\mathrm{s}}+E_{\mathrm{f}} A_{\mathrm{f}}\right)}=\frac{E_{\mathrm{f}} A_{\mathrm{f}}}{E_{\mathrm{sf}} A_{\mathrm{sf}}}, \\
\rho_{\mathrm{sf}}^{\mathrm{e}} & =\frac{E_{\mathrm{f}} A_{\mathrm{f}}}{r_{\mathrm{sf}} E_{\mathrm{s}} A_{\mathrm{g}}},
\end{aligned}
$$

where $E_{\mathrm{f}}$ and $A_{\mathrm{f}}$ are the elastic modulus of outer FRP and the cross-sectional area of the outer FRP, respectively; $E_{\mathrm{s}}$ and $A_{\mathrm{s}}$ are the elastic modulus of the inner steel bar and the crosssectional area of the inner steel bar, respectively; $E_{\mathrm{sf}}$ and $A_{\mathrm{sf}}$ are the elastic modulus of SFCB and the cross-sectional area of SFCB, respectively; and $A_{\mathrm{g}}$ is the total cross-sectional area of the concrete beam.

2.2. The Comparison between the Tested and the Calculated Results for Concrete Beams. The specimen details are presented in Figure 3: the total length of the beam is $2000 \mathrm{~mm}$, the cross section was $220 \mathrm{~mm} \times 300 \mathrm{~mm}$, and the shearspan ratio was 3 . The diameter of the top bars was $12 \mathrm{~mm}$ diameter, the diameter of the stirrups was $8 \mathrm{~mm}$ diameter, and the average tested compressive strength of six concrete cubes $(150 \times 150 \times 150 \mathrm{~mm})$ was $48.8 \mathrm{MPa}$ [20].

The longitudinal reinforcements of the selected concrete beams were steel bar and S10B51, and the corresponding mechanical properties are listed in Table 1 . The notation "S10B51" indicates that the SFCB is composed of an inner steel bar with a diameter of $10 \mathrm{~mm}$ that is longitudinally wrapped by 51 bundles of 4000 -tex basalt fibers, where "tex" is the weight ( $\mathrm{g}$ ) of one fiber bundle per kilometer. The elastic modulus of a steel bar is approximately $200 \mathrm{GPa}$, and that of a basalt fiber is nearly $90 \mathrm{GPa}$. As a result, the elastic modulus of an SFCB is smaller than that of a steel bar [19].

Five groups of dial gauges were evenly arranged on the front side of the mid-span, and five strain gauges were also installed on the opposite side with the same height (Figure $4(\mathrm{a})$ ) to verify the plane section assumption. The average strain of B-S10B51 that was measured by the dial gauges is presented in Figure 4(b): the horizontal axis represents microstrain and the vertical axis represents the distance from the beam's bottom surface. The average strain of B-S10B51 along the section height can satisfy the plane section assumption, and the neutral axis was substantially unchanged before cracking and increased rapidly after cracking. Although the composite bar S10B51 had stable postyield stiffness, the neutral axis rapidly increases after the yielding of the inner steel bar to resist the increased moment. 
TABLE 1: Mechanical properties of the selected reinforcements.

\begin{tabular}{lcccccc}
\hline Reinforcement type & $d(\mathrm{~mm})$ & $E_{\mathrm{I}}(\mathrm{GPa})$ & $E_{\mathrm{II}}(\mathrm{GPa})$ & $f_{\mathrm{y}}(\mathrm{MPa})$ & $f_{\mathrm{u}}(\mathrm{MPa})$ & Elongation rate $(\%)$ \\
\hline Steel bar & 12 & 204 & $/$ & 415 & 580 & 14.5 \\
S10B51 & 18 & 96.13 & 29.80 & 192.27 & 548.4 & 2.6 \\
\hline
\end{tabular}
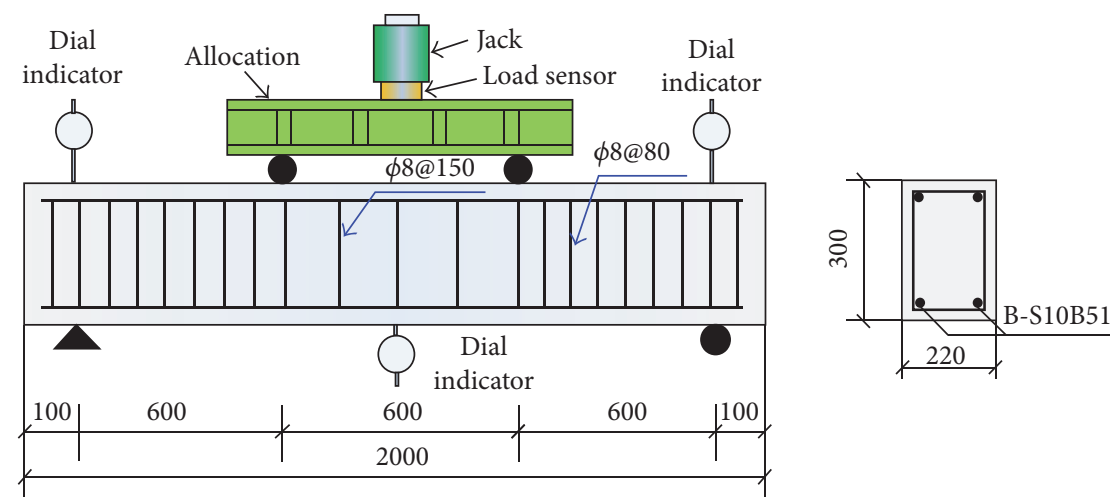

Figure 3: Specimen design.

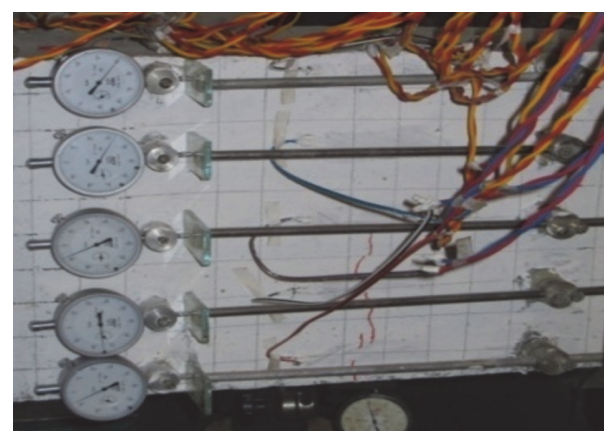

(a) Measurement of average strain at mid-span

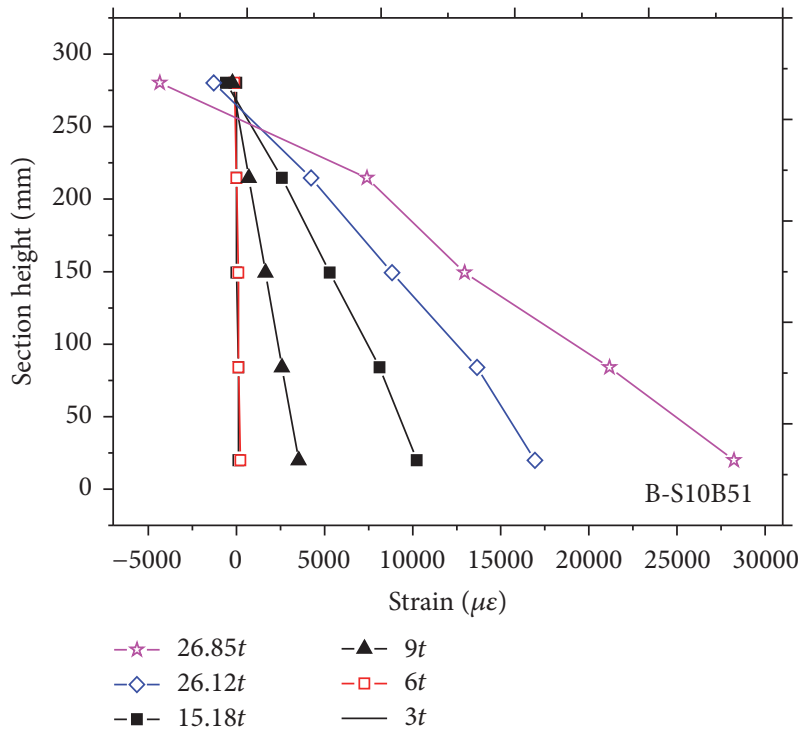

(b) The strain distribution of B-S10B51

Figure 4: Verification of the plane section assumption of B-S10B51.

With verification of the plain section assumption, the average curvatures of the SFCB-reinforced concrete beam can be calculated by

$$
\phi=\frac{\varepsilon_{\mathrm{c}}+\varepsilon_{\mathrm{sf}}}{h_{0}}
$$

where $\varepsilon_{\mathrm{c}}$ (absolute value) is the concrete compressive strain and $h_{0}$ is the effective height of the beam's cross section. As a result, MPPC $\phi_{\text {peak_max }}$ of a hybrid reinforced beam can be determined by the FRP rupture strain $\varepsilon_{\mathrm{FRP}}$, the section effective height $h_{0}$, and the ultimate compressive strain of concrete $\varepsilon_{\mathrm{cu}}$.
The tested stress-strain curve of the composite bar S10B51 and the corresponding calculated curve by OS are shown in Figure 5(a); the calculated curve was consistent with the tested value. As shown in Figure 5(b), the comparison between the calculated results and the tested results for a concrete beam reinforced by SFCB is presented, in which the yield strength and the ultimate strength of S10B51 were taken as $80 \%$ of the tested values. The calculated bearing capacity corresponded with the test results, whereas the corresponding ultimate mid-span displacement is approximately $81 \%$ of the tested values, which is caused by the large slip between the SFCB and the concrete at mid-span (Figure 6). 


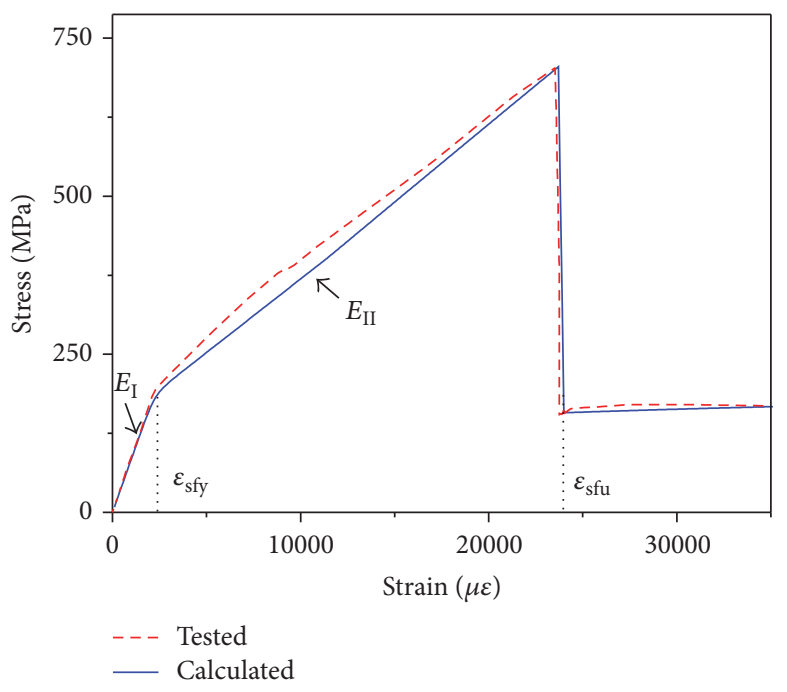

(a) Mechanical properties

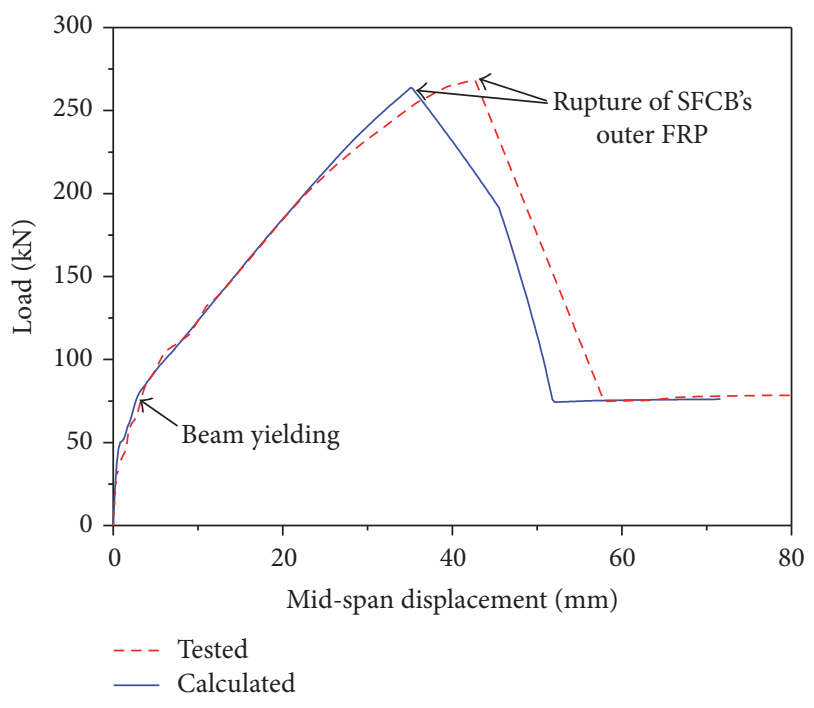

(b) SFCB-reinforced concrete beam

FIGURE 5: Comparison between tested results and calculated results of SFCB-reinforced concrete beam.
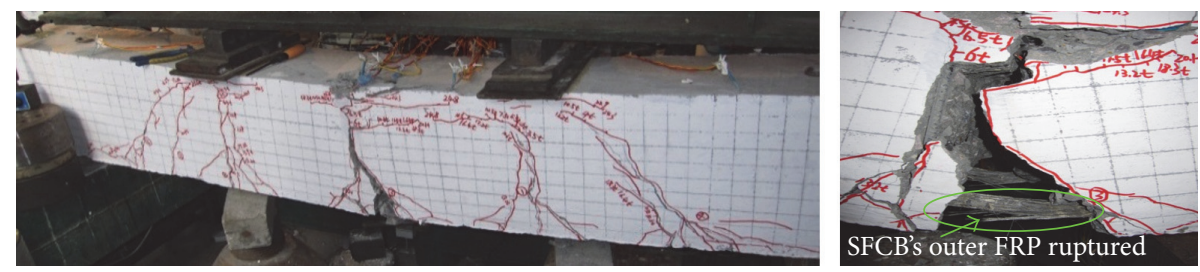

FIGURE 6: Failure mode of B-S10B51.

2.3. Critical Reinforcement Ratio. The calculation method of the RC beam can also be employed for beams that are reinforced by SFCB or hybrid FRP bar/steel bar. The failure mode of SFCB-reinforced concrete beam can be influenced by the yield strain of SFCB, FRP rupture strain, and concrete crush strain. The different ultimate state (strain distribution) of hybrid reinforced concrete beam is shown in Figure 7(a), where the tensile capacity of cracked concrete is assumed to be zero. The failure mode can be divided into three cases according to the dominated parameters, $\varepsilon_{\mathrm{sfu}}$ or $\varepsilon_{\mathrm{cu}}$. When the equivalent reinforcement ratio $\rho_{\mathrm{sf}}^{\mathrm{e}}$ exceeds $\rho_{\mathrm{b}_{\mathrm{I}}}^{\mathrm{e}}$, the failure mode (Mode I) is concrete crushed before the tensile reinforcement reached yield strain. When the ultimate state is concrete crushed after SFCB's inner steel bar yielded (without FRP rupture), the reinforcement ratio ranges between $\rho_{\mathrm{b}_{-} \mathrm{I}}^{\mathrm{e}}$ and $\rho_{\mathrm{b} \text { II }}^{\mathrm{e}}$ (Mode II). The third failure mode is the SFCB's outer FRP rupture after the inner steel yielded without concrete crushing (Mode III), and the corresponding $\rho_{\text {sf }}^{\mathrm{e}}$ is smaller than $\rho_{\mathrm{b} \_I I}^{\mathrm{e}}$. When the failure mode includes concrete crushing, the compression stress of concrete can be simplified as a rectangular block (Figure $7(\mathrm{~b})$ ), the average stress intensity is expressed as $\alpha_{1} f_{c}^{\prime}$, and the compression height of concrete block can be represented as $\beta_{1} x_{c}$.

According to the static equilibrium of axial force and the plain section assumption, the critical reinforcement ratios $\left(\rho_{\mathrm{b}_{-} \mathrm{I}}^{\mathrm{e}}\right.$ and $\left.\rho_{\mathrm{b} \_\mathrm{II}}^{\mathrm{e}}\right)$ of SFCB-reinforced concrete beam can be calculated by equations (8) and (9) [25]:

$$
\begin{aligned}
& \rho_{\mathrm{b}_{-} \mathrm{I}}^{\mathrm{e}}=\alpha_{1} \beta_{1} \frac{f_{\mathrm{c}}^{\prime}}{E_{\mathrm{s}}} \frac{1}{\varepsilon_{\mathrm{sfy}}\left(1+\varepsilon_{\mathrm{sfy}} / \varepsilon_{\mathrm{cu}}\right)}, \\
& \rho_{\mathrm{b}_{-} \mathrm{II}}^{\mathrm{e}}=\alpha_{1} \beta_{1} \frac{f_{\mathrm{c}}^{\prime}}{E_{\mathrm{s}}} \frac{1}{\left[\left(\varepsilon_{\mathrm{sfu}}-\varepsilon_{\mathrm{sfy}}\right) r_{\mathrm{sf}}+\varepsilon_{\mathrm{sfy}}\right]\left(1+\varepsilon_{\mathrm{sfu}} / \varepsilon_{\mathrm{cu}}\right)},
\end{aligned}
$$

where $\alpha_{1}$ and $\beta_{1}$ are coefficients for the equivalent stress block of concrete in compression.

\section{Parametric Study}

3.1. Typical Moment-Curvature Curves of the SFCB Beam. According to the design code of AASHTO [26], the selected parameters are as follows: the width of the beam section $b=200 \mathrm{~mm}$; the aspect ratio $h / b=2 \sim 4 ; \rho_{\mathrm{sf}}^{\mathrm{e}}=0.3 \% \sim 1.2 \%$; $f_{\mathrm{c}}^{\prime}=30 \sim 90 \mathrm{MPa}$; the rupture strain of SFCB's outer FRP $\varepsilon_{\text {sf }}=0.015 \sim 0.025$, which represent carbon fiber $(0.015)$ to basalt fiber (0.025); and the postyield stiffness ratio of SFCB $r_{\text {sf }}=0.001 \sim 0.95$. A total of 2880 moment-curvature analyses were performed in this paper; typical moment-curvature curves are illustrated in Figure 8 by varying $r_{\text {sf }}$. With an increase in $r_{\text {sf }}$, the yield point remained stable, the postyield stiffness increased, and the peak curvature $\left(\phi_{\text {peak }}\right)$ increased 


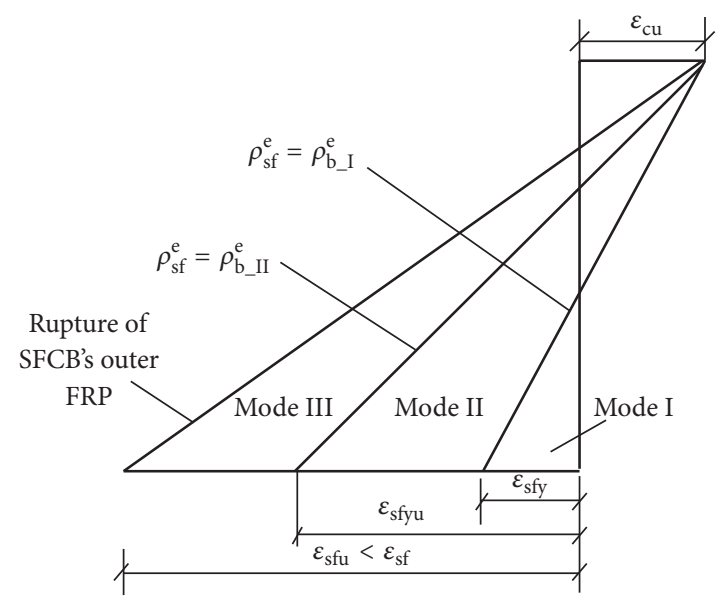

(a) Strain distribution of different failure modes

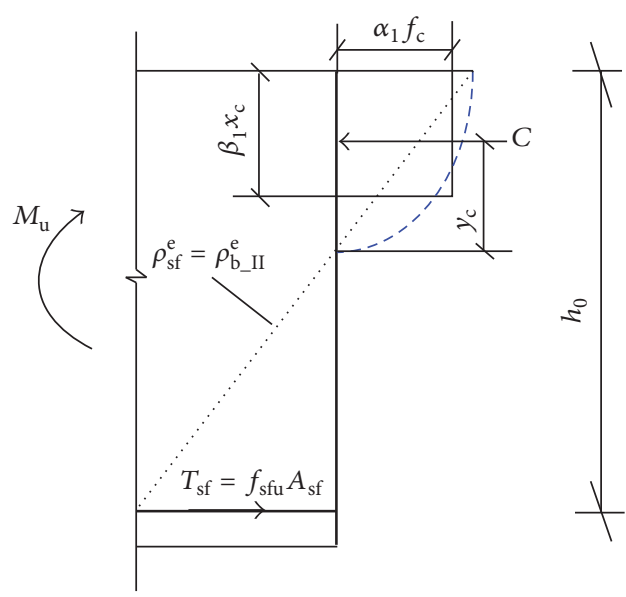

(b) Equivalent stress block of internal relationships at $\phi_{\text {peak_max }}$

FIGURE 7: Schematic strain distribution and equivalent concrete stress block.

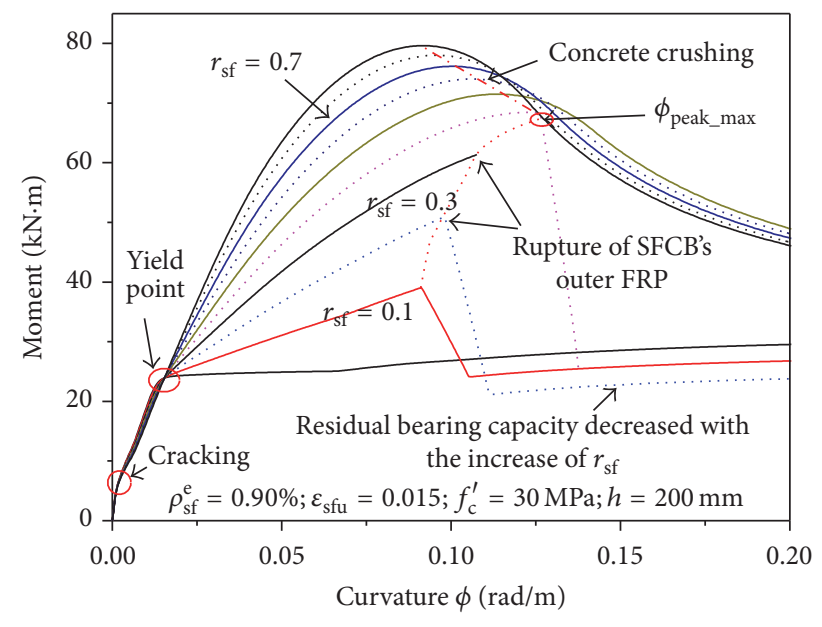

Figure 8: Moment-curvature analyses of SFCB beams.

and then decreased. Before the ultimate curvature reached $\phi_{\text {peak_max }}$, the increase of $\phi_{\text {peak }}$ is caused by a decrease in the concrete compression depth, and the failure mode is concrete crushing. As a result, the ultimate curvature is dominated by the tensile strain of SFCB in this failure mode. After the rupture of SFCB's outer FRP, the moment decreased to the level in which only the inner steel bar worked, and the inner steel bar decreased with an increase in the $r_{\mathrm{sf}}$.

3.2. Yield Point. The yield moment increases with an increase in $\rho_{\mathrm{sf}}^{\mathrm{e}}$, whereas the yield curvature slightly decreased. With an increase in the concrete compressive strength, both the yield moment and the yield curvature increased. A semiempirical equation was proposed by Aycardi et al. [27] with consideration of the effect of yield strain and effective depth, as shown in

$$
\phi_{\mathrm{y}}=1.7 \frac{f_{\mathrm{y}}}{E_{\mathrm{s}} h_{0}}=1.7 \frac{\varepsilon_{\mathrm{sfy}}}{h_{0}} .
$$

Because the yield strain and the column depth are fixed parameters, the key parameter is the concrete strain when tensile reinforcement yielded. The fitted yield curvature is presented in (11) with consideration of the reinforcement ratio and concrete strength:

$$
\phi_{\text {y_regress }} h_{0}=\varepsilon_{\text {sfy }}+0.0396 \rho_{\text {sf }}^{\mathrm{e}}+0.00035 .
$$

The comparison between the fitted results and the yield curvature by OS is shown in Figure 9(a). Aycardi's empirical equation overestimated the yield curvature, the proposed (11) is consistent with the results of OS, and the coefficient of determination $\left(R^{2}\right)$ of the fitted equation is 0.997 .

The fitted yield moment can be obtained based on the fitted yield curvature and the sectional force balance, as shown in

$$
\frac{M_{\text {y_regress }}}{E_{s} b h_{0}^{2}}=0.00157 \rho_{\text {sf }}^{\mathrm{e}}+6.233 E-07,
$$

where $M_{\text {y_regress }}$ is the fitted moment. Figure 9(b) presents the comparison between the fitted results and the OS values; $R^{2}$ is 0.998 .

3.3. Ultimate Point. The ultimate point of a conventional RC structure was defined by $80 \%$ or $85 \%$ of the peak load capacity. For SFCB-reinforced concrete structures, the rupture of SFCB's outer FRP will cause a significant decrease in the load capacity. As a result, the rupture of SFCB's outer FRP was defined as the ultimate point of SFCB-reinforced concrete beam in this paper.

3.3.1. The Influence of the Reinforcement Ratio. Before the section curvature reached $\phi_{\text {peak_max }}$, both the ultimate moment and curvature increase with an increase in $\rho_{\mathrm{sf}}^{\mathrm{e}}$ (Figure 10(a)). With an increase in $r_{\text {sf }}$, the section ultimate curvature with a larger $\rho_{\mathrm{sf}}^{\mathrm{e}}$ increases faster than the section ultimate curvature with a smaller $\rho_{\mathrm{sf}}^{\mathrm{e}}$. When the section ultimate curvature 


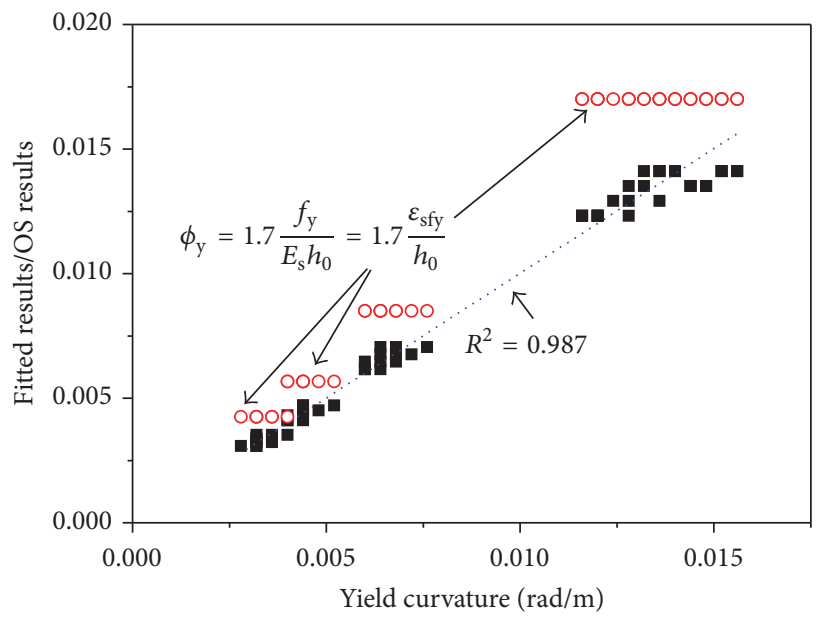

(a) Curvature

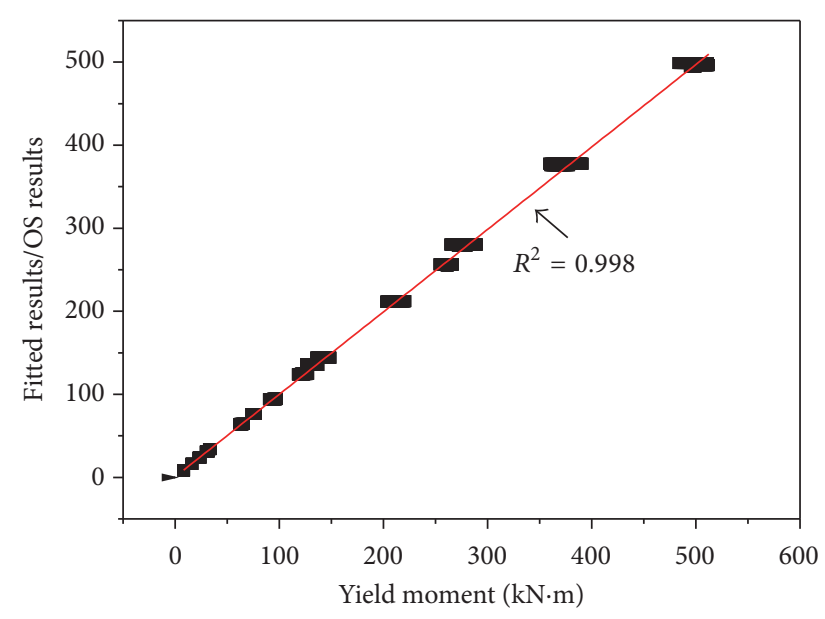

(b) Moment

FIGURE 9: Fitted results of yield curvature and moment.

reached $\phi_{\text {peak_max }}$, the larger $\rho_{\mathrm{sf}}^{\mathrm{e}}$ is, the smaller the corresponding $r_{\text {sf }}$ is. As illustrated in Figure 10(b), when the $\rho_{\text {sf }}^{\mathrm{e}}$ increased from $0.3 \%$ to $0.9 \%$, $\phi_{\text {peak_max }}$ decreased from $0.65 \mathrm{rad} / \mathrm{m}$ to $0.15 \mathrm{rad} / \mathrm{m}$ (reduced by $77 \%$ ). After the curvature reached $\phi_{\text {peak_max }}$, with an increase in $r_{\text {sf }}$, the section moment continued to increase while the curvature significantly decreased, which was caused by a decrease in the tensile strain of SFCB at the ultimate point.

The dimensionless ultimate moment and curvature are shown in Figures 10(c) and 10(d). Before reaching the critical point $\left(\phi_{\text {peak max }}\right)$, the slopes of the dimensionless moments almost overlap. When $r_{\mathrm{sf}}$ was fixed as 0.1 , the ultimate curvatures were approximately ten times the yield curvature when other parameters changed. Before the ultimate curvature reached $\phi_{\text {peak_max }}$, with an increase in $r_{\text {sf }}$, both the slope and the dimensionless value of the section moment with larger $\rho_{\mathrm{sf}}^{\mathrm{e}}$ decreased. The trend of the dimensionless curvature (Figure 10(d)) was similar to the trend of the original curvature (Figure 10(b)). As a result, only the dimensionless curvature was discussed when changing other parameters.

3.3.2. The Influence of SFCB's Rupture Strain. The rupture strain of SFCB's outer FRP has no effect on the yield curvature or moment. The dimensionless moments and curvatures of the SFCB beam section by changing the rupture strain of SFCB were presented in Figure 11; the failure modes are Mode II and Mode III. When failure Mode II occurred, the ultimate point was determined by the concrete crush strain. As a result, the ultimate moment and curvature with different SFCB rupture strains were equivalent. In Mode III, the larger the SFCB's rupture strain was, the larger the ultimate moment and curvature were. With an increase in $r_{\mathrm{sf}}$, the ultimate curvature increased at a faster rate than the rate of increase in the ultimate moment, which was caused by the nonlinear property of concrete stress-strain in the compression zone.

3.3.3. The Influence of Effective Depth. When the effective depth $\left(h_{0}\right)$ increases and other parameters remain unchanged, both the ultimate moment and the ultimate curvature will increase with an increase in $h_{0}$. However, $r_{\text {sf }}$ (approximately to 0.25 ) does not change when the ultimate point reached critical point $\phi_{\text {peak_max }}$. The dimensionless moment and curvature are also listed in Figure 12, and the dimensionless curves almost overlap.

3.4. Curvature before MPPC. The failure is determined by the rupture strain of SFCB's outer FRP in failure Mode III, and the concrete in the compression zone kept undamaged. Based on the force equilibrium and elastic assumption, the concrete strain can be obtained as shown in

$$
\varepsilon_{\mathrm{c}}=\phi_{\mathrm{u}} h_{0}-\varepsilon_{\mathrm{sfu}}=\frac{\gamma_{1}+\sqrt{\gamma_{1}^{2}+4 \gamma_{1} \varepsilon_{\mathrm{sfu}}}}{2},
$$

where $\gamma_{1}$ can be expressed as

$$
\gamma_{1}=\frac{2 E_{\mathrm{sf}}^{\mathrm{e}}}{E_{\mathrm{c}}} \rho_{\mathrm{sf}}^{\mathrm{e}}\left[\varepsilon_{\mathrm{y}}+r_{\mathrm{sf}}\left(\varepsilon_{\mathrm{sfu}}-\varepsilon_{\mathrm{y}}\right)\right] .
$$

The comparison between the calculated ultimate curvature and the corresponding OS curvature is shown in Figure 13.

The calculated curvatures correspond with the corresponding OS results when $r_{\text {sf }}$ is relatively small. The calculated curvatures became smaller than the calculated curvatures in OS when $r_{\text {sf }}$ is large (Figure 13(a)). The error was caused by the elastic assumption of compressive concrete, which enlarges the contribution of compressive concrete, and, therefore, the calculated ultimate curvature was underestimated when $r_{\text {sf }}$ is relatively large. The compressive strain of concrete will increase with an increase in the reinforcement ratio (Figure 13(b)), an increase in SFCB's rupture strain (Figure 13(c)), or a decrease in $f_{c}^{\prime}$ (Figure 13(d)), which will produce a larger error between the calculated values and OS values; the maximum error is approximately $30 \%$.

3.5. The Maximum Possible Curvature (MPPC). A total of 98 sets of ultimate points were observed around the maximum 


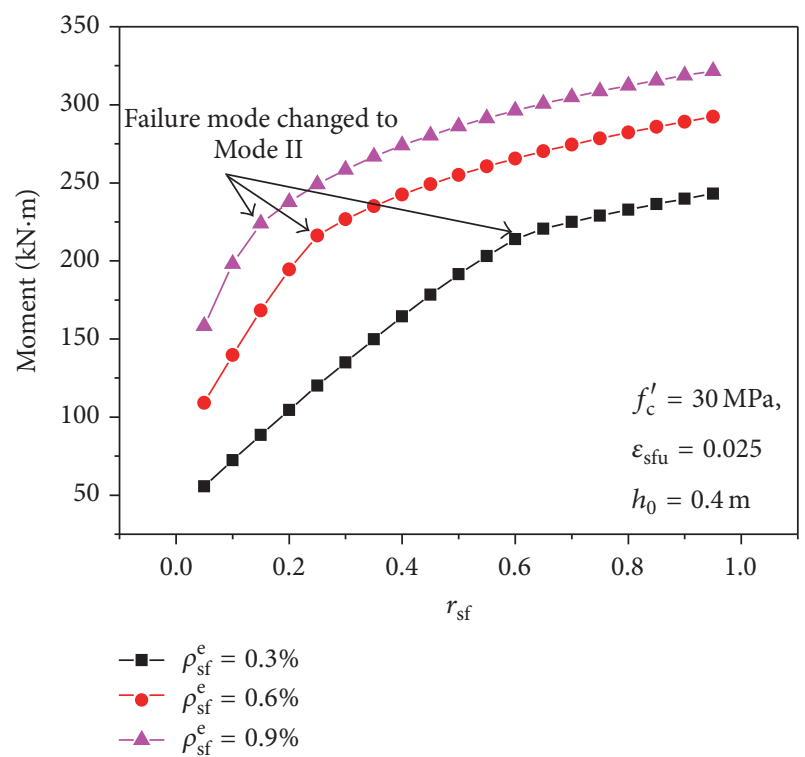

(a) $r_{\text {sf }}$ - moment

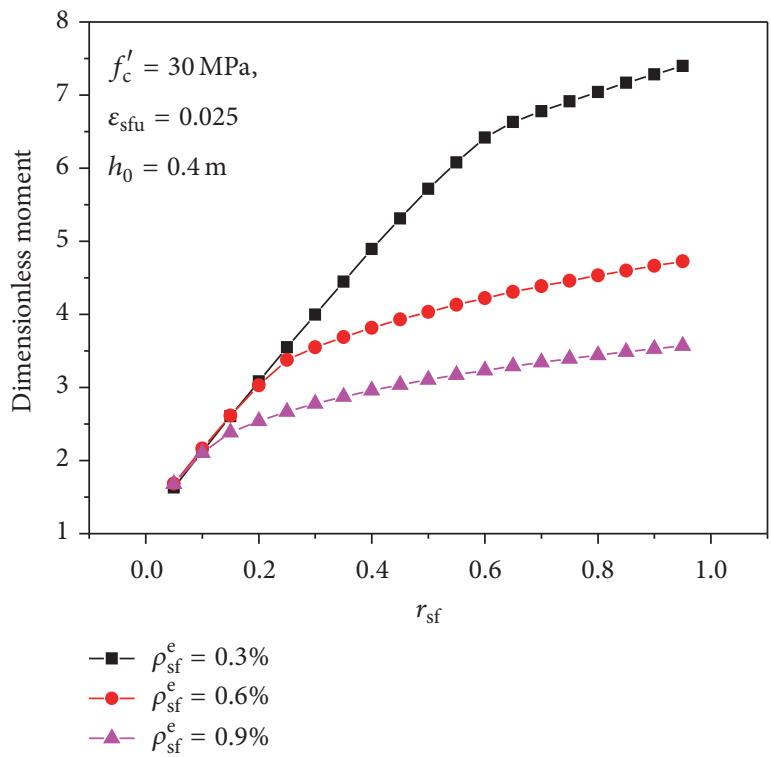

(c) $r_{\mathrm{sf}}$ - dimensionless moment

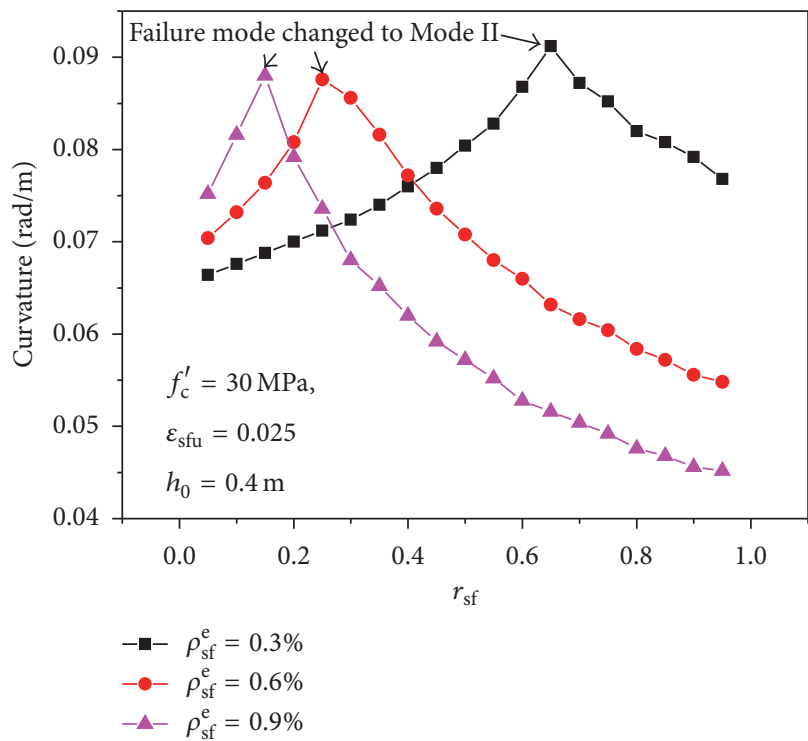

(b) $r_{\text {sf }}$ - curvature

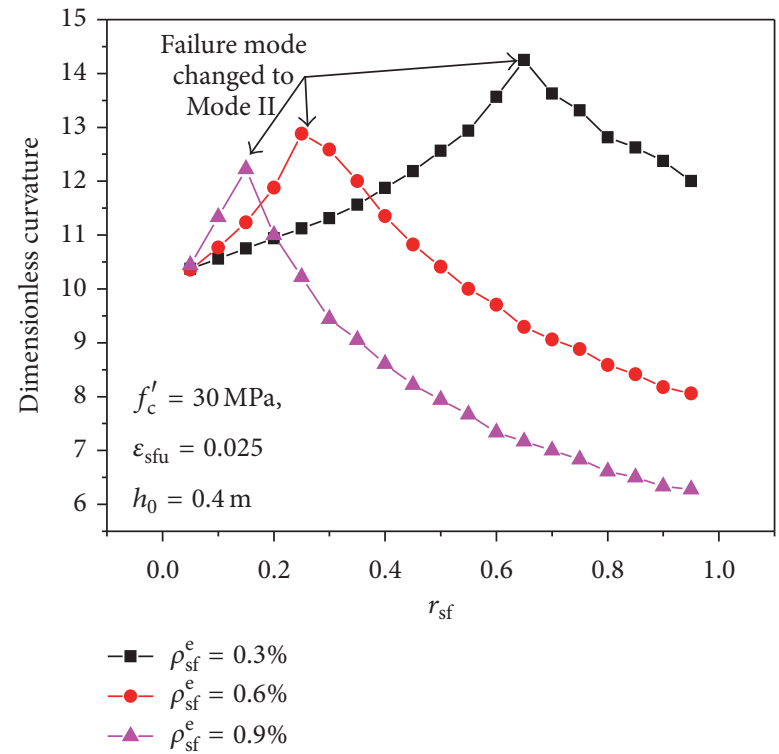

(d) $r_{\mathrm{sf}}$ - dimensionless curvature

FIGURE 10: Influence of the reinforcement ratio.

possible peak curvature. The comparison between the calculated $\phi_{\text {peak_max }}$ using (7) and the corresponding curvature in OS is shown in Figure 14(a), where the former was generally larger than the latter. The maximum error was approximately $20 \%$, which was primarily caused by the error in concrete compressive strain. The fitted $\phi_{\text {peak_max }}$ is listed in (15), and the corresponding comparison between the fitted value and the OS results is presented in Figure 14(a), which indicates that (15) can yield a better prediction of $\phi_{\text {peak_max }}$ :

$$
\phi_{\text {peak_max }}=\frac{\varepsilon_{\text {sfu }}+0.985 \varepsilon_{\mathrm{cu}}-0.0045}{h_{0}} .
$$

When the section curvature reached $\phi_{\text {peak max }}$, the corresponding reinforcement ratio $\rho_{\mathrm{sf}}^{\mathrm{e}}$ is $\rho_{\mathrm{b}-\mathrm{II}}^{\mathrm{e}}$ (Figure $7(\mathrm{a})$ ). The calculated $\rho_{\mathrm{b} \text { II }}^{\mathrm{e}}$ by (9) was larger than $\rho_{\mathrm{b} \text { II }}^{\mathrm{e}}$ in OS; the maximum error was approximately $40 \%$ (Figure $14(\mathrm{~b})$ ). Equation (16) is the fitted critical reinforcement ratio $\left(\rho_{\text {b_II_regress }}^{\mathrm{e}}\right)$ by the regression in concrete compressive strain:

$\rho_{\mathrm{b} \_I I \_r e g r e s s}^{\mathrm{e}}$

$$
\begin{aligned}
= & \frac{f_{\mathrm{c}}^{\prime}}{E_{\mathrm{s}}\left(1+\varepsilon_{\mathrm{sfu}} / \varepsilon_{\mathrm{cu}}\right)\left(\varepsilon_{\mathrm{s}_{\text {sfu }}}-\varepsilon_{\mathrm{sfy}}\right)} \\
& \times \frac{1}{\left[1.379\left(\varepsilon_{\mathrm{sfy}_{\mathrm{sfy}}} /\left(\varepsilon_{\mathrm{s}_{\mathrm{sfu}}}-\varepsilon_{\mathrm{sfy}}\right)\right)+1.278 r_{\mathrm{sf}}-0.003\right]} .
\end{aligned}
$$




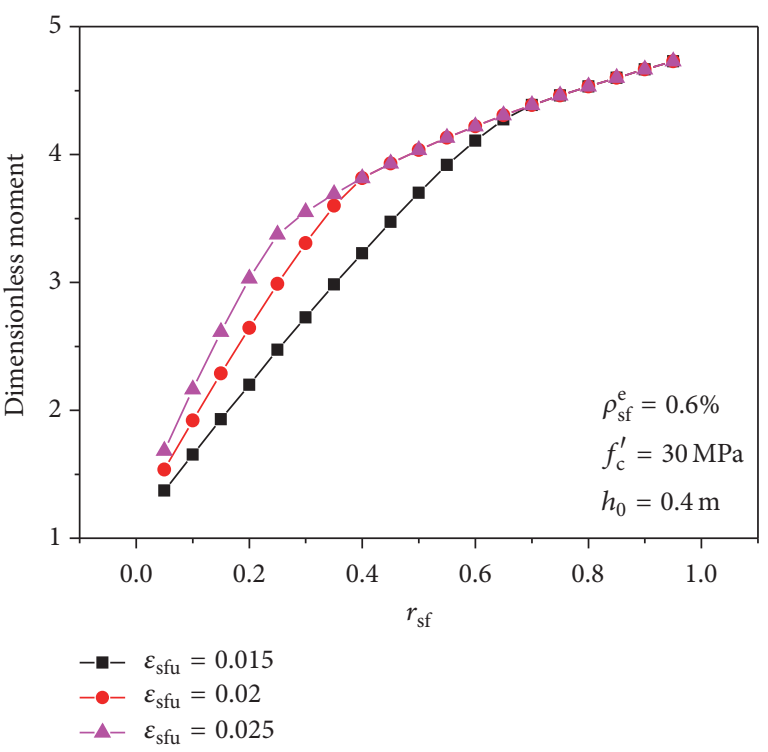

(a) $r_{\text {sf }}$ - dimensionless moment

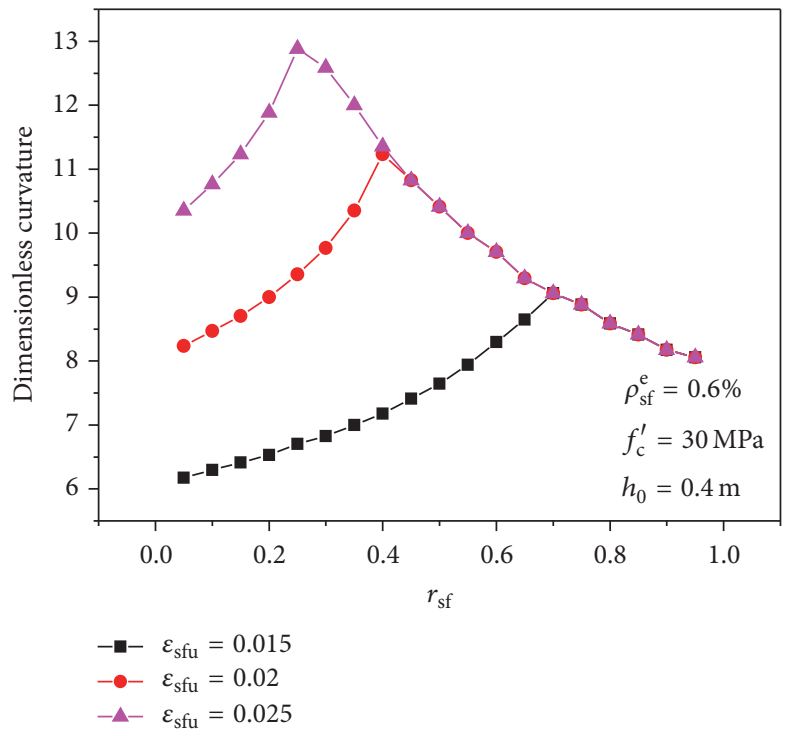

(b) $r_{\mathrm{sf}}$ - dimensionless curvature

FIGURE 11: Influence of SFCB's rupture strain.

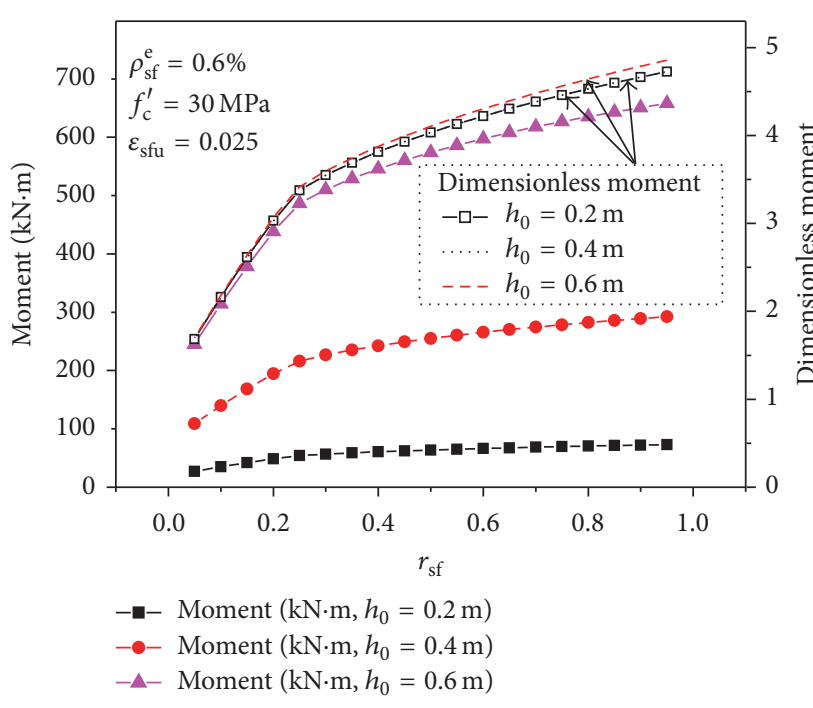

(a) $r_{\text {sf }}$-moment

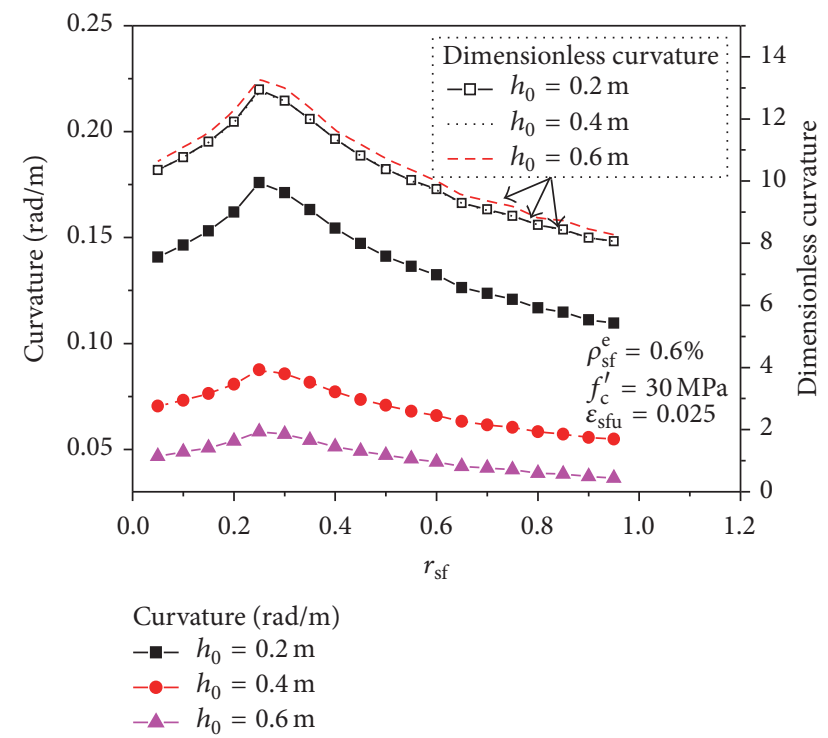

(b) $r_{\mathrm{sf}}$-curvature

FIGURE 12: Influence of effective depth.

The comparison between $\rho_{\mathrm{b}-I I / r e g r e s s}^{\mathrm{e}}$ and the reinforcement ratio in OS is illustrated in Figure 14(b). The error was \pm 10 percent, which indicates that (16) can be used to predict the failure mode of a designed concrete beam that is reinforced by SFCB.

3.6. Curvature after MPPC. After the ultimate curvature reached $\phi_{\text {peak_max }}$, the ultimate curvature will decrease with an increase in $r_{\mathrm{sf}}$, and the corresponding failure mode is concrete crushing (Mode III). Based on the force equilibrium and the simplified compression block, the tensile strain of SFCB can be calculated by

$$
\varepsilon_{\mathrm{sf}}=\frac{-\gamma_{2}+\sqrt{\gamma_{2}^{2}-8 r_{\mathrm{sf}} \gamma_{3}}}{2 r_{\mathrm{sf}}},
$$

where $\gamma_{2}$ and $\gamma_{3}$ can be expressed by (18) and (19), respectively:

$$
\gamma_{2}=\varepsilon_{\mathrm{y}}\left(1-r_{\mathrm{sf}}\right)+\varepsilon_{\mathrm{cu}} r_{\mathrm{sf}}
$$




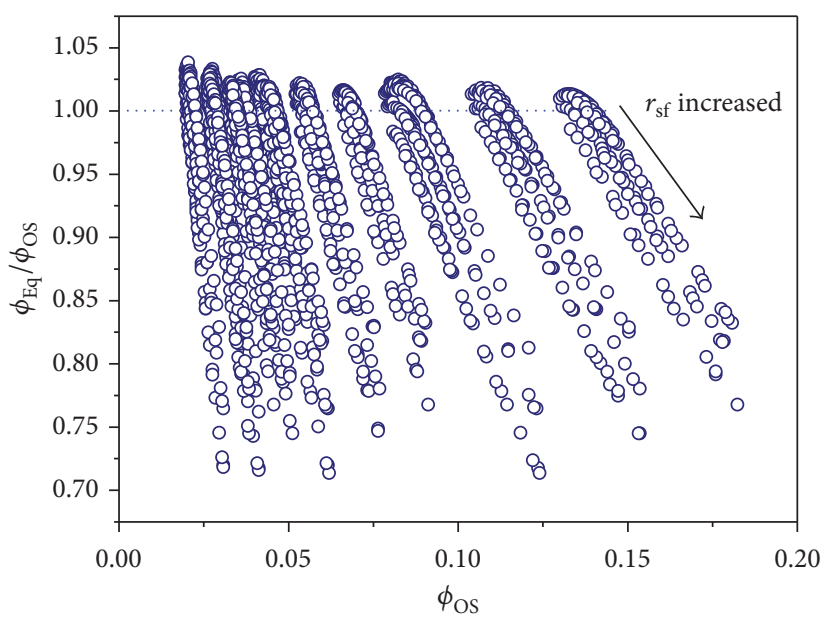

(a) All data

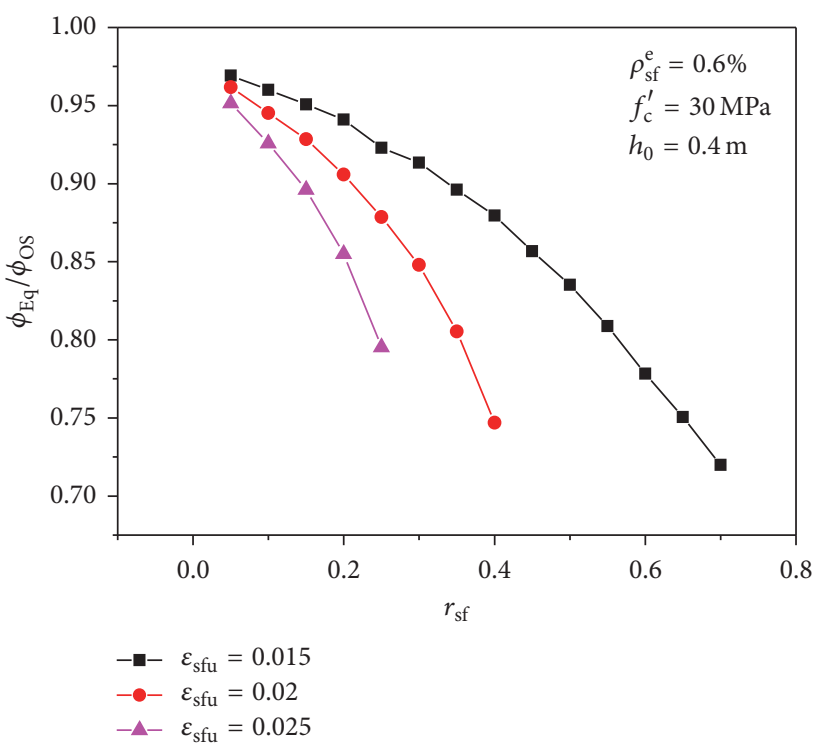

(c) Different SFCB's rupture strain

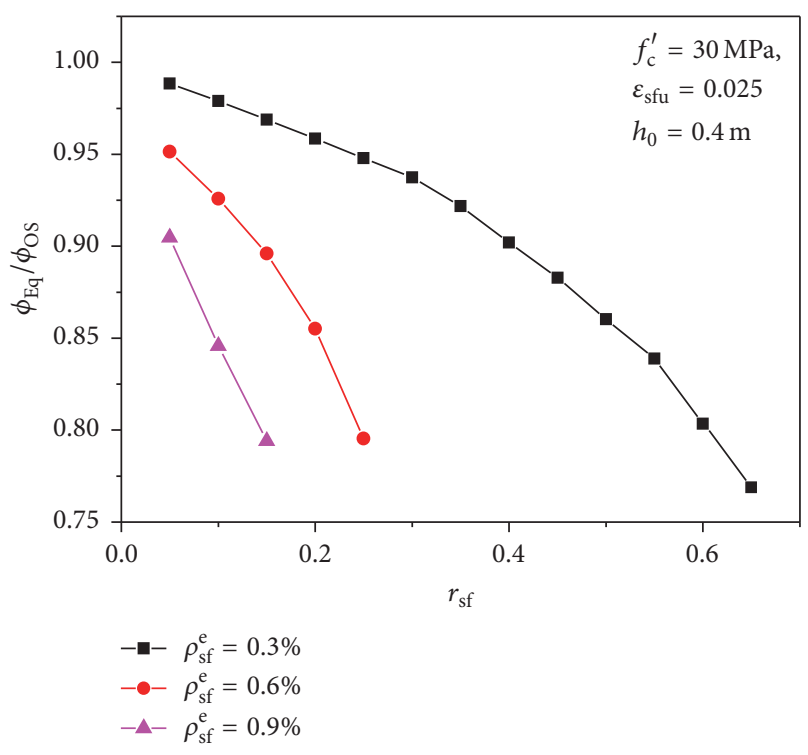

(b) Different reinforcement ratio

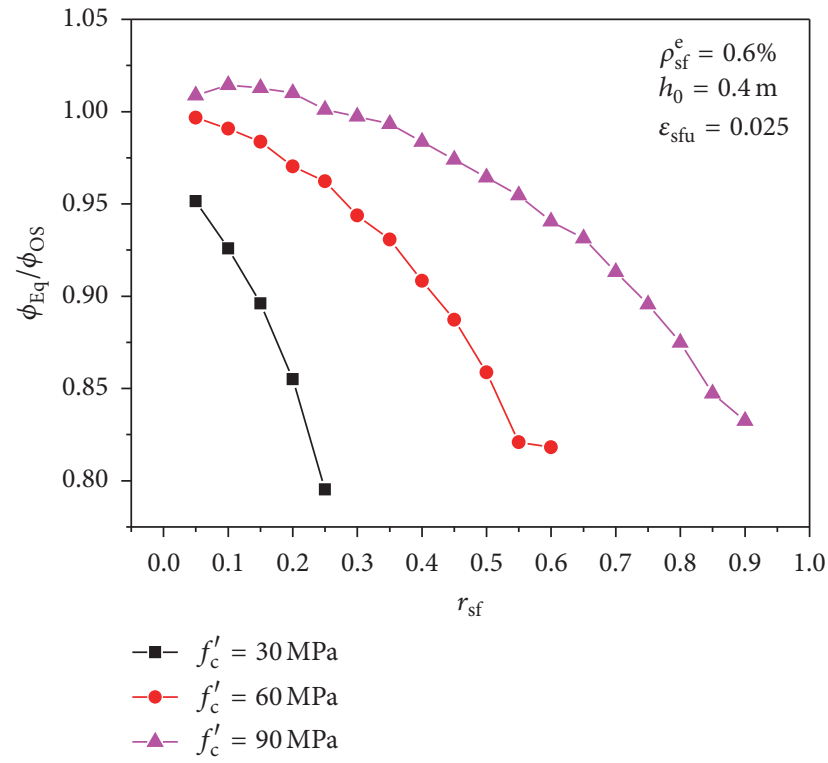

(d) Different $f_{\mathrm{c}}^{\prime}$

FIGURE 13: Comparison between the calculated curvatures and the corresponding OS results in failure Mode III.

$$
\gamma_{3}=\varepsilon_{\mathrm{cu}} \varepsilon_{\mathrm{y}}\left(1-r_{\mathrm{sf}}\right)-\frac{f_{\mathrm{c}} \varepsilon_{\mathrm{cu}}}{E_{\mathrm{sf}}^{\mathrm{e}} \rho_{\mathrm{sf}}^{\mathrm{e}}} .
$$

The comparison between the calculated curvatures by (17) and the OS values is presented in Figure 15. When the curvature ductility is relatively large, the calculated curvature was similar to the OS results. When the curvature ductility is relatively small, the calculated curvature may be approximately 1.35 times the calculated curvature of the OS values, and $\phi_{\text {calculated }} / \phi_{\text {peak_max_os }}$ is approximately a power function of the curvature ductility (Figure 15).

\section{Discussion of Curvature Ductility}

Many indexes were proposed for the performance evaluation of a conventional RC structure; ductility is a main index but the ductility substantially varied because the yield curvature (displacement) that was obtained using different methods significantly varied $[28,29]$. The yield point can be determined by the graphing method and the equal energy method, as shown in Figure 16. For a SFCB beam, the yield curvature is determined by the yield of the inner steel bar, and the ultimate curvature is defined by the rupture of SFCB's outer FRP or the crushing of concrete in the compression zone. 


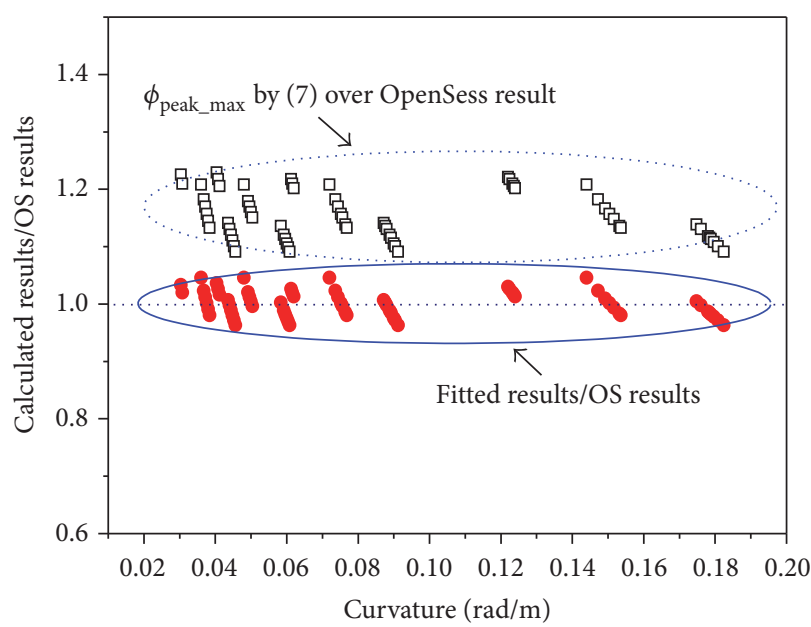

(a) Comparison between the calculated $\phi_{\text {peak_max }}$ and the corresponding OS results

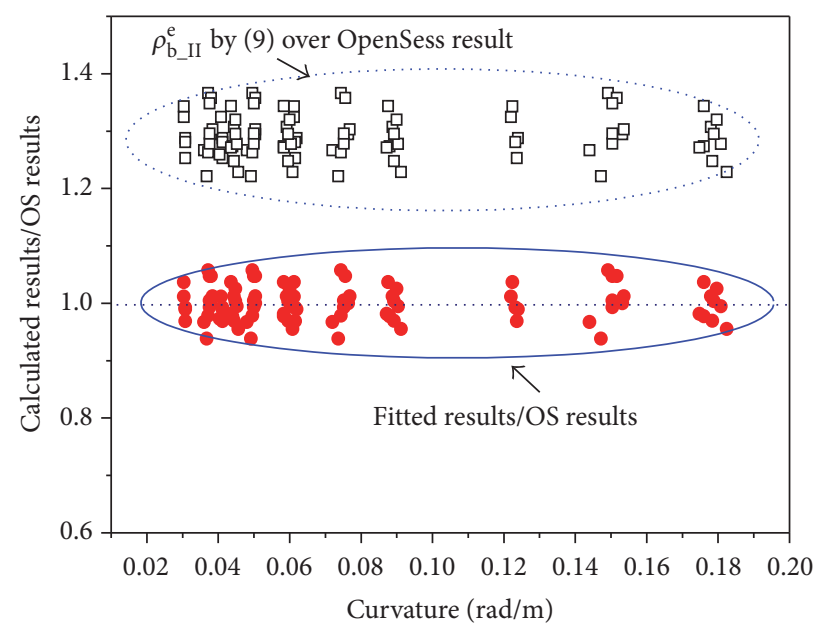

(b) Comparison of the critical reinforcement ratio $\rho_{\mathrm{sf}}^{\mathrm{e}}$

FIGURE 14: Maximum possible peak curvature and critical reinforcement ratio.

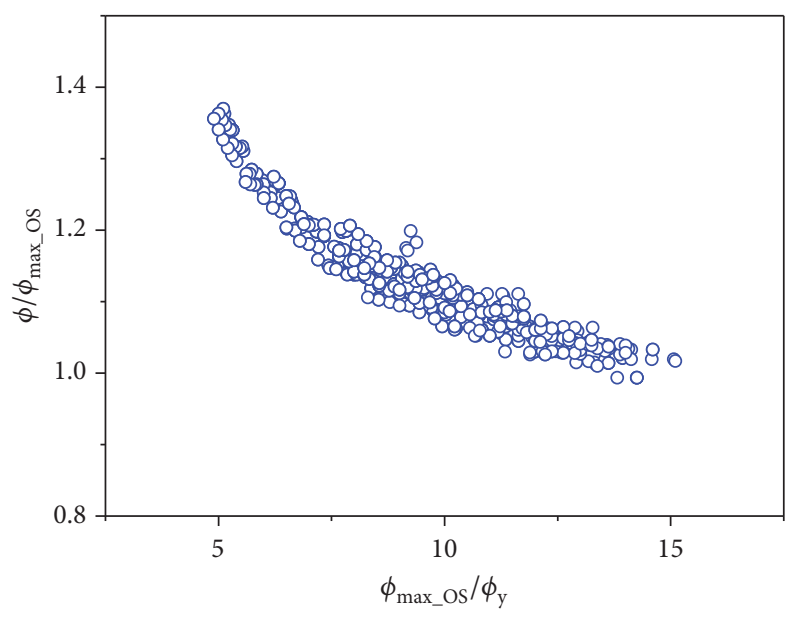

FIGURE 15: Comparison between the calculated curvatures and the OS values in Mode II.

The differences among different ductility factors are calculated using (20) to (22), where $\mu_{1}$ is the ratio between the yield curvature and ultimate curvature (see (20)), $\mu_{2}$ is a ductility index that considers the effect of the ultimate moment (see (21)), and $\mu_{3}$ is the ratio of the total envelope area and the area before yielding (see (22)):

$$
\begin{aligned}
& \mu_{1}=\frac{\phi_{\mathrm{u}}}{\phi_{\mathrm{y}}}, \\
& \mu_{2}=\frac{M_{\mathrm{u}} \phi_{\mathrm{u}}}{M_{\mathrm{y}} \phi_{\mathrm{y}}}, \\
& \mu_{3}=\frac{E_{\mathrm{tot}}}{E_{\mathrm{y}}}=\frac{\phi_{\mathrm{u}}}{\phi_{\mathrm{y}}}-\frac{M_{\mathrm{u}}}{M_{\mathrm{y}}}+\frac{M_{\mathrm{u}} \phi_{\mathrm{u}}}{M_{\mathrm{y}} \phi_{\mathrm{y}}} .
\end{aligned}
$$

The development trend of $\mu_{1}, \mu_{2}$, and $\mu_{3}$ is presented in Figure 17(a): when the failure mode was SFCB's outer
FRP rupture, the three ductility indexes increased with an increase in $r_{\text {sf }}$, and $\mu_{3}$ has the largest absolute value. When the failure mode was concrete crushing, the three ductility indexes decreased with an increase in $r_{\text {sf }}$; the largest ductility was observed at the point of the MPPC. Figure 17(b) presents the development trend of "dimensionless" ductility $\left(\mu / \mu_{r_{\mathrm{sf}}=0.05}\right)$ : compared with the slopes before MPPC, the decreasing slope of "dimensionless" $\mu_{1}$ was the largest, and the decreasing slope of "dimensionless" $\mu_{2}$ was comparatively flat. For "dimensionless" $\mu_{3}$, both the ultimate moment and the ultimate curvature were considered, and the decreasing slope of "dimensionless" $\mu_{3}$ ranged between "dimensionless" $\mu_{1}$ and "dimensionless" $\mu_{2}$.

The influence of $\rho_{\mathrm{sf}}^{\mathrm{e}}, \varepsilon_{\mathrm{sfu}}, f_{\mathrm{c}}^{\prime}$, and $h_{0}$ on $\mu_{3}$ is shown in Figure 18. When the failure mode is the rupture of SFCB's outer FRP (Mode III), $\rho_{\mathrm{sf}}^{\mathrm{e}}, f_{\mathrm{c}}^{\prime}$, and $h_{0}$ have a minimal influence on $\mu_{3}$. By changing the rupture strain of SFCB $\varepsilon_{\text {sfu }}$, the slope of $\mu_{3}$ increases with an increase in $r_{\text {sf }}$, which is caused by the increased ultimate moment and ultimate curvature. When the failure mode was concrete crushing after the yielding of SFCB's inner steel (Mode II), the ductility varies within a relatively small range, $\mu_{3}$ decreases with an increase in $r_{\text {sf }}$, and $f_{\mathrm{c}}^{\prime}$ and $\varepsilon_{\mathrm{sfu}}$ had minimal influence on the softening branch. The "dimensionless" $\mu_{3}\left(\gamma_{\mu}=\mu_{3} / \mu_{3 r_{\mathrm{sf}}=0.05}\right)$ was not affected by changes in $h_{0}$ (Figure $18(\mathrm{~d})$ ), and $\mu_{3}$ was approximately 4.3 times $\mu_{1}$ when the MPPC was attained.

\section{Conclusions}

Based on the simulation of the test results of a concrete beam reinforced by SFCB, the parametric analysis of momentcurvature behavior of singly reinforced concrete beams was conducted according to AASHTO design code. The main conclusions are as follows:

(1) The failure modes of a concrete beam reinforced by SFCB including concrete crushing before the tensile reinforcement reached yield strain (Mode I), concrete 


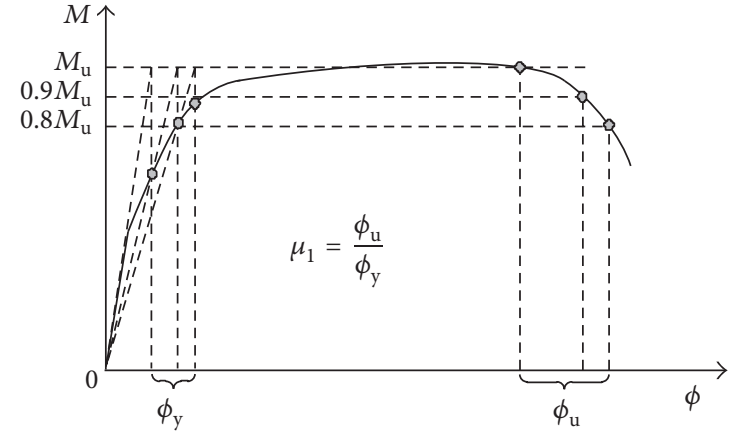

(a) Different methods to determine yield point and ultimate point

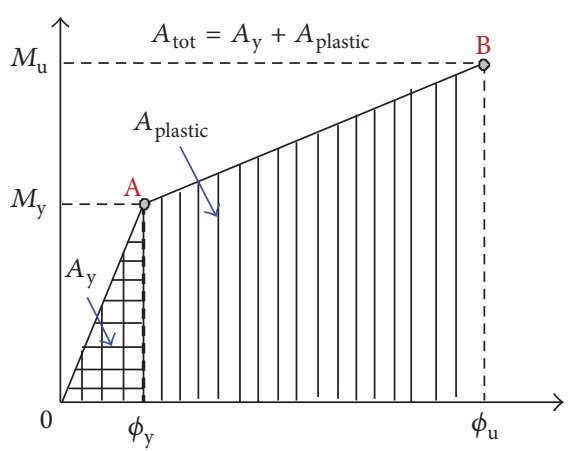

(b) Ductility defined by energy

Figure 16: Different methods for defining ductility.

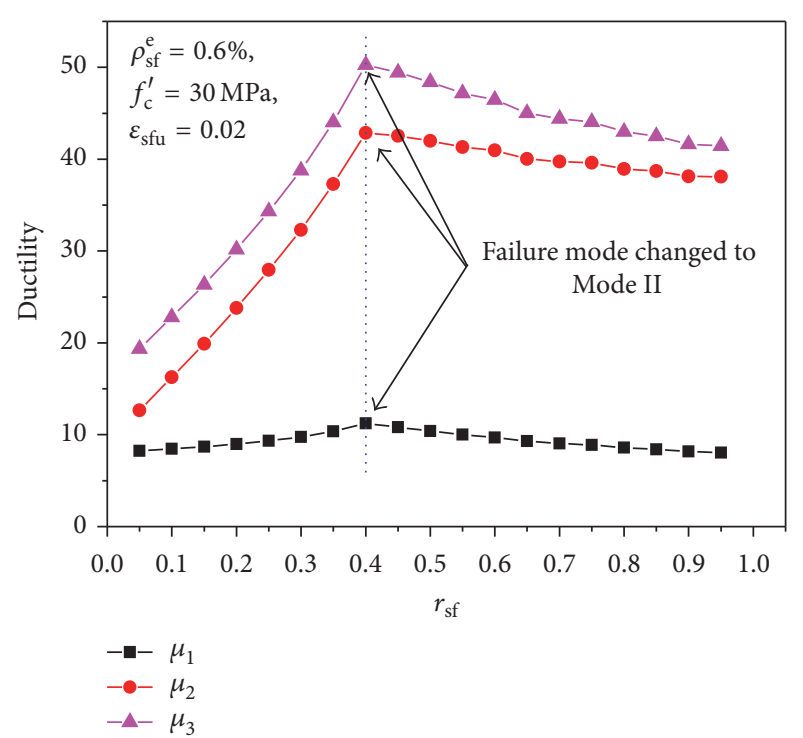

(a) Differences among $\mu_{1}, \mu_{2}$, and $\mu_{3}$

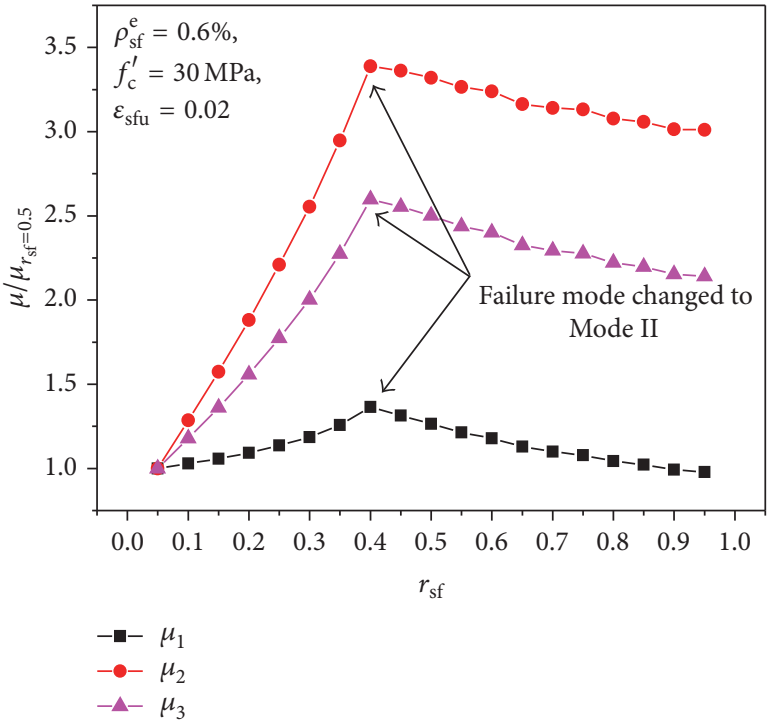

(b) "Dimensionless" ductility

FIGURE 17: Comparison of $\mu_{1}, \mu_{2}$, and $\mu_{3}$.

crushed after SFCB's inner steel bar yielded (without outer FRP fiber ruptured, Mode II), and the SFCB's outer FRP ruptured after the inner steel yielded without concrete crushing (Mode III). In addition, the ultimate curvature increases with an increase in $r_{\mathrm{sf}}$ in failure Mode III, whereas the ultimate curvature decreases with an increase in $r_{\text {sf }}$ in failure Mode II.

(2) When the rupture of SFCB's outer FRP accompanied the crushing of concrete in the compression zone, the section reached the MPPC and the corresponding parameters were critical for the ductility of a concrete beam. Before reaching the MPPC, the calculated ultimate curvature was consistent with the OpenSees (OS) results when $r_{\text {sf }}$ was relatively small, and the ultimate curvature was underestimated with an increase in $r_{\mathrm{sf}}$. After reaching the MPPC, the calculated curvature corresponds with the OS results when the curvature ductility is large, and the curvature will be overestimated when the curvature ductility is comparatively small.

(3) The curvature ductility with consideration of the envelope area can reflect an increase in the ultimate moment when $r_{\text {sf }}$ is large, and the sectional curvature ductility can be justified by changing $r_{\mathrm{sf}}, \varepsilon_{\mathrm{sfu}}, \rho_{\mathrm{sf}}^{\mathrm{e}}, f_{\mathrm{c}}^{\prime}$, and $h_{0}$. Before reaching the MPPC, $\rho_{\mathrm{sf}}^{\mathrm{e}}, f_{\mathrm{c}}^{\prime}$, and $h_{0}$ have a minimal influence on the "dimensionless" $\mu_{3}$. After reaching the MPPC, $\mu_{3}$ slightly decreased with an increase in $r_{\mathrm{sf}}$. For the design of SFCB-reinforced concrete beams, Mode II is preferred without SFCB's outer FRP rupture, and the bearing capacity and ductility of concrete beams are considered synthetically. 


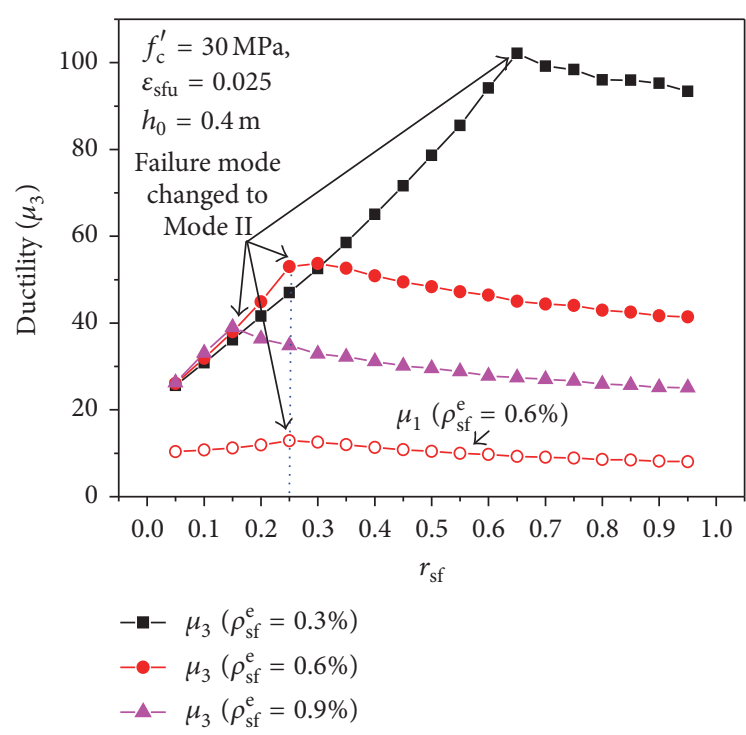

(a) Change reinforcement ratio

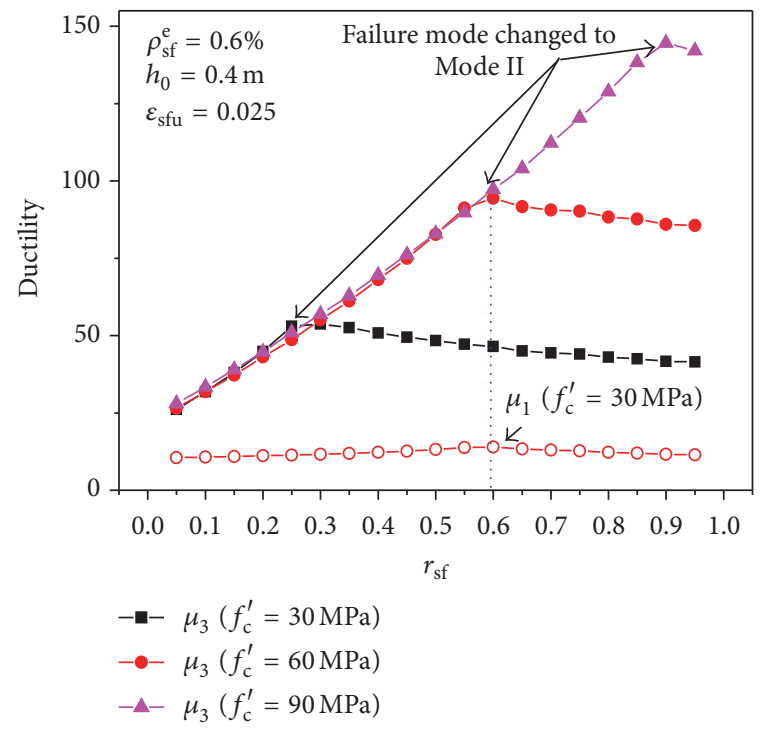

(c) Change $f_{\mathrm{c}}^{\prime}$

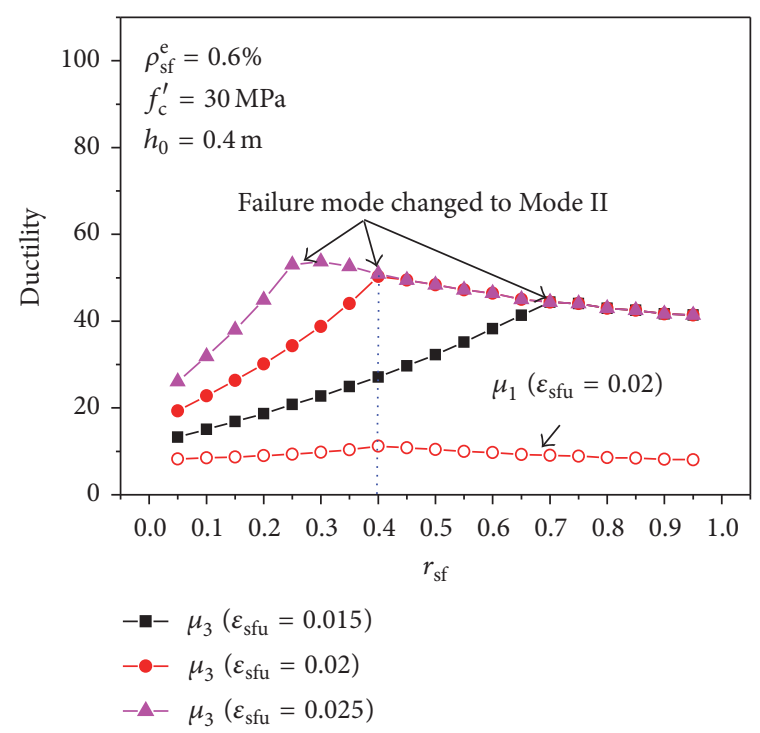

(b) Change SFCB rupture strain

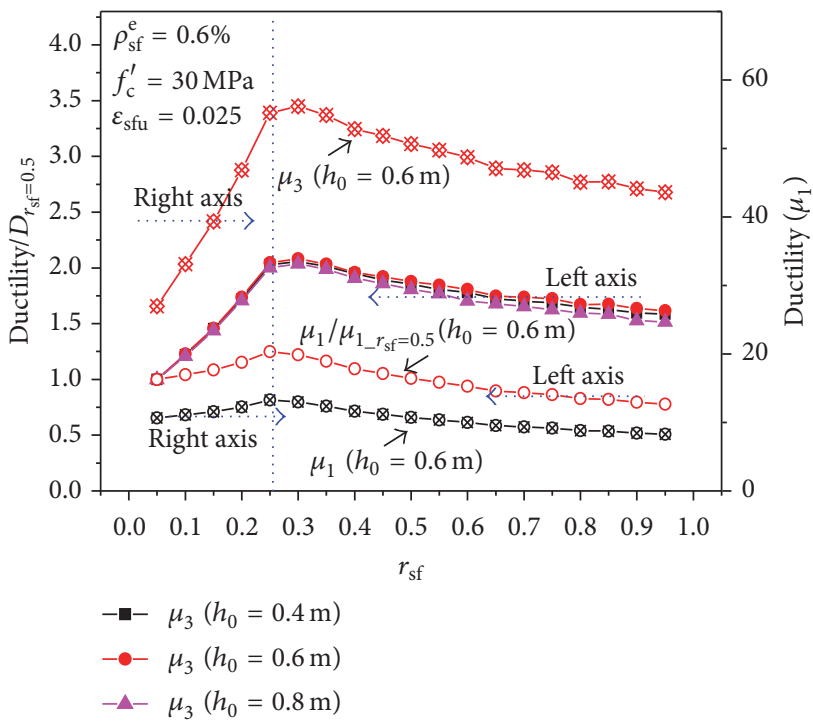

(d) Change $h_{0}$

FIGURE 18: Comparison of $\mu_{3}$ with different parameters.

\section{Competing Interests}

The authors declare that they have no competing interests.

\section{Acknowledgments}

The authors acknowledge the financial support from the National Key Technology Support Program of China (2014BAK11B04), the National Natural Science Foundation of China (nos. 51408126 and 51528802), the Natural Science Foundation of Jiangsu Province, China (no. BK20140631), and Project Funding from the Priority Academic Program Development of Jiangsu Higher Education Institutions (CE01-2-3).

\section{References}

[1] S. Dong, B. Zhao, C. Lin, R. Du, R. Hu, and G. X. Zhang, "Corrosion behavior of epoxy/zinc duplex coated rebar embedded in concrete in ocean environment," Construction and Building Materials, vol. 28, no. 1, pp. 72-78, 2012.

[2] C. E. Bakis, L. C. Bank, V. L. Brown et al., "Fiber-reinforced polymer composites for construction-state-of-the-art review," Journal of Composites for Construction, vol. 6, no. 2, pp. 73-87, 2002.

[3] X. Huang, J. Wang, F. Zhang, S.-S. Niu, and J. Ding, "An experimental investigation on the failure behavior of a notched concrete beam strengthened with carbon fiber-reinforced polymer," International Journal of Polymer Science, vol. 2015, Article ID 729320, 17 pages, 2015. 
[4] B. Benmokrane, O. Chaallal, and R. Masmoudi, "Flexural response of concrete beams reinforced with FRP reinforcing bars," ACI Structural Journal, vol. 93, no. 1, pp. 46-55, 1996.

[5] ACI Committee 318, Building Code Requirements for Structural Concrete (ACI 318-05) and Commentary (ACI 318-89), American Concrete Institute, Detroit, Mich, USA, 1989.

[6] A. A. Mufti, N. Banthia, B. Benmokrane, M. Boulfiza, and J. P. Newhook, "Durability of GFRP composite rods," Concrete International, vol. 29, no. 2, pp. 37-42, 2007.

[7] Canadian Standards Association, Canadian Highways Bridge Design Code, Section 16, Fiber Reinforced Structures, Canadian Standards Association, Ottawa, Canada, 2000.

[8] ACI 440.4R-04, Prestressing Concrete Structures with FRP Tendons, vol. 440, ACI Committee, Farmington Hills, Mich, USA, 2004.

[9] E. E.-S. Etman, "Innovative hybrid reinforcement for flexural members," Journal of Composites for Construction, vol. 15, no. 1, pp. 2-8, 2011.

[10] D. Lau and H. J. Pam, "Experimental study of hybrid FRP reinforced concrete beams," Engineering Structures, vol. 32, no. 12, pp. 3857-3865, 2010.

[11] ACI, "Guide for the design and construction of concrete reinforced with FRP bars," ACI 440.1R-06, American Concrete Institute, Detroit, Mich, USA, 2006.

[12] M. A. Safan, "Flexural behavior and design of steel-GFRP reinforced concrete beams," ACI Materials Journal, vol. 110, no. 6, pp. 677-685, 2013.

[13] L. Pang, W. Qu, P. Zhu, and J. Xu, "Design propositions for hybrid FRP-steel reinforced concrete beams," Journal of Composites for Construction, ASCE, vol. 20, no. 4, pp. 1-9, 2015.

[14] A. El Refai, F. Abed, and A. Al-Rahmani, "Structural performance and serviceability of concrete beams reinforced with hybrid (GFRP and steel) bars," Construction and Building Materials, vol. 96, pp. 518-529, 2015.

[15] A. Nanni, M. J. Henneke, and T. Okamoto, "Behaviour of concrete beams with hybrid reinforcement," Construction and Building Materials, vol. 8, no. 2, pp. 89-95, 1994.

[16] B. Saikia, J. Thomas, A. Ramaswamy, and K. S. Nanjunda Rao, "Performance of hybrid rebars as longitudinal reinforcement in normal strength concrete," Materials and Structures, vol. 38, no. 10, pp. 857-864, 2005.

[17] G. Wu, Z. S. Wu, Y. B. Luo, and H. C. Wei, "A new reinforcement material of steel fiber composite bar (SFCB) and its mechanics properties," in Proceedings of 9th International Symposium on 'Fiber Reinforced Polymer (FRP) Reinforcement for Concrete Structures' (FRPRCS '09), University of Adelaide, Adelaide, Australia, July 2009.

[18] Z.-Y. Sun, G. Wu, Z.-S. Wu, and J. Zhang, "Nonlinear behavior and simulation of concrete columns reinforced by steel-FRP composite bars," Journal of Bridge Engineering, vol. 19, no. 2, pp. 220-234, 2014.

[19] G. Wu, Z.-S. Wu, Y.-B. Luo, Z.-Y. Sun, and X.-Q. Hu, "Mechanical properties of steel-frp composite bar under uniaxial and cyclic tensile loads," Journal of Materials in Civil Engineering, vol. 22, no. 10, Article ID 010010QMT, pp. 1056-1066, 2010.

[20] Z. Y. Sun, Y. Yang, W. H. Qin, S. T. Ren, and G. Wu, "Experimental study on flexural behavior of concrete beams reinforced by steel-fiber reinforced polymer composite bars," Journal of Reinforced Plastics and Composites, vol. 31, no. 24, pp. 1737-1745, 2012.
[21] M. Andreou, A. Kotsoglou, and S. Pantazopoulou, "Modelling blast effects on a reinforced concrete bridge," Advances in Civil Engineering, vol. 2016, Article ID 4167329, 11 pages, 2016.

[22] S. Mazzoni, F. McKenne, M. H. Scott, and G. L. Fenves, Open System for Earthquake Engineering Simulation User Manual Version 2.0., Pacific Earthquake Engineering Center, University of California, Berkeley, Calif, USA, 2009, http://opensees.berkeley.edu/OpenSees/manuals/usermanual/index.html.

[23] H. M. Yassin Mohd, Nonlinear analysis of prestressed concrete structures under monotonic and cyclic [Ph.D. thesis], University of California, Berkeley, Calif, USA, 1994.

[24] G. A. Chang and J. B. Mander, "Seismic energy based fatigue damage analysis of bridge beams: part I-evaluation of seismic capacity," NCEER Technical Report 94-0006, NCEER/State University of New York at Buffalo, Buffalo, NY, USA, 1994.

[25] Z. Sun, W. Xiao, G. Wu, and Z. Wu, "Study on moment-curvature behavior of concrete column reinforced by steel-fiber reinforced polymer composite bars," in Proceedings of 12th International Symposium on Fiber Reinforced Polymers for Reinforced Concrete Structures (FRPRCS '12) \& The 5th Asia-Pacific Conference on Fiber Reinforced Polymers in Structures (APFIS '15), Nanjing, China, December 2015.

[26] AASHTO, AASTO LRFD Bridge Design Specifications (SI Units), American Association of State Highway and Transportation Officials, Washington, DC, USA, 3rd edition, 2004.

[27] L. E. Aycardi, J. B. Mander, and A. M. Reinhorn, "Seismic resistance of reinforced concrete frame structures designed only for gravity loads: experimental performance of subassemblages," ACI Materials Journal, vol. 91, no. 5, pp. 552-563, 1994.

[28] F. Oudah and R. El-Hacha, "A new ductility model of reinforced concrete beams strengthened using Fiber Reinforced Polymer reinforcement," Composites Part B: Engineering, vol. 43, no. 8, pp. 3338-3347, 2012.

[29] Z. Sun, G. Wu, J. Zhang, Y. Zeng, and W. Xiao, "Experimental study on concrete columns reinforced by hybrid steel-fiber reinforced polymer (FRP) bars under horizontal cyclic loading," Construction and Building Materials, vol. 130, pp. 202-211, 2017. 


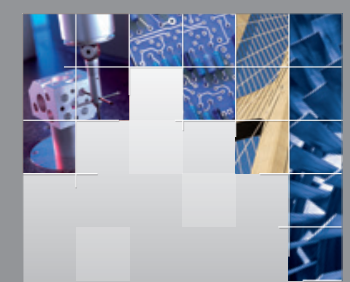

\section{Enfincering}
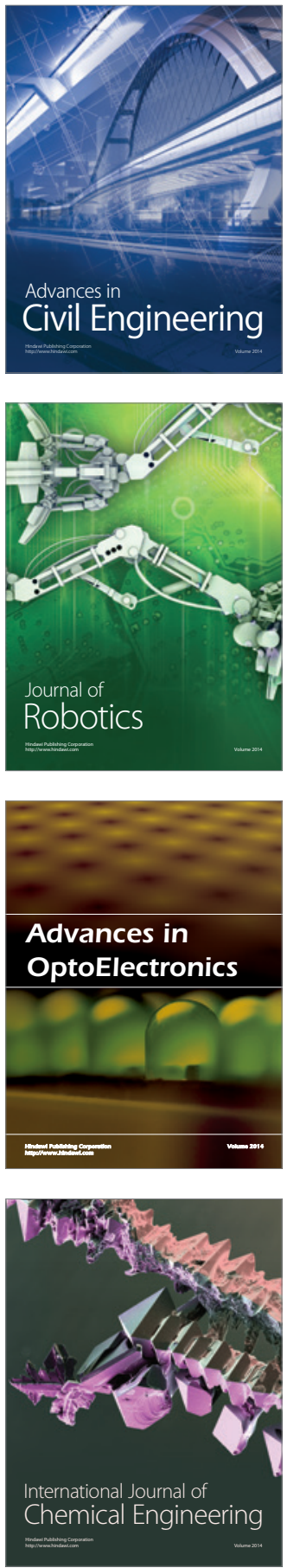

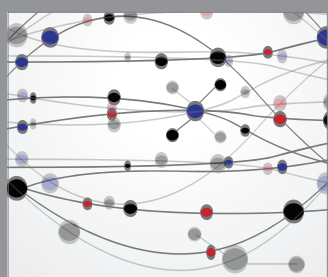

The Scientific World Journal

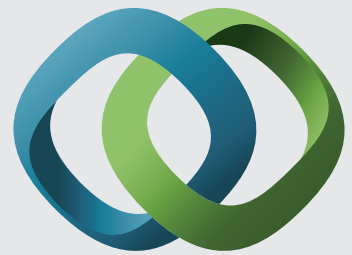

\section{Hindawi}

Submit your manuscripts at

https://www.hindawi.com
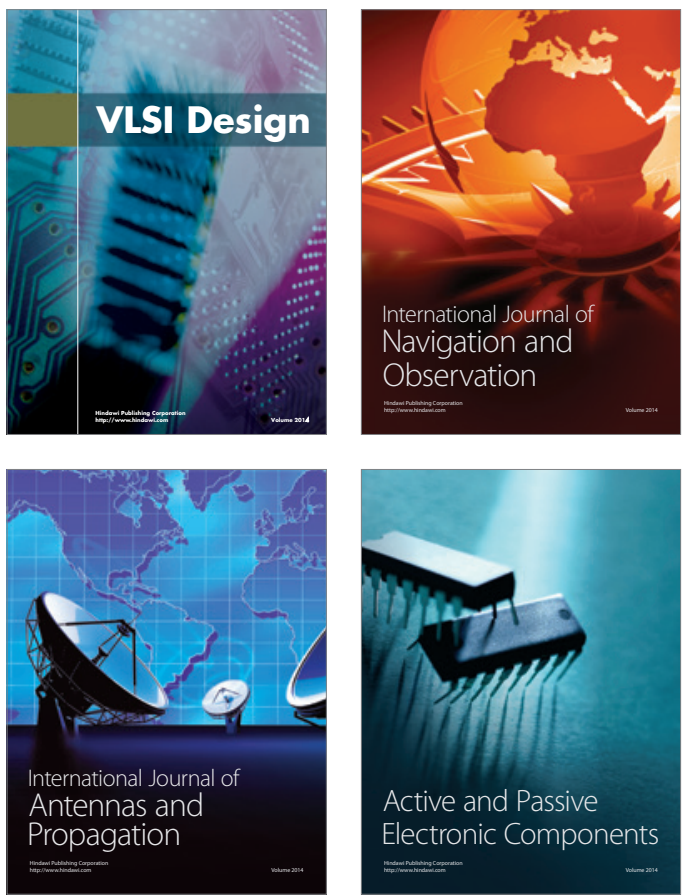
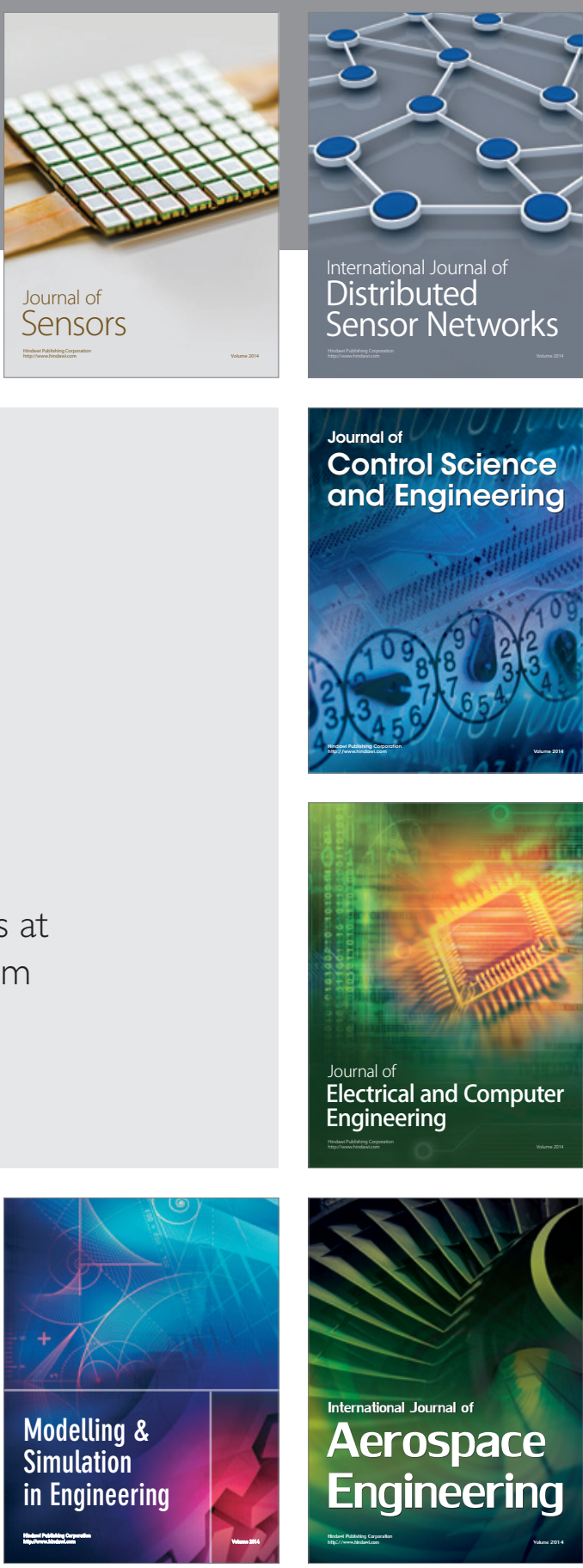

International Journal of

Distributed

Sensor Networks

$-$

Joumal of

Control Science

and Engineering
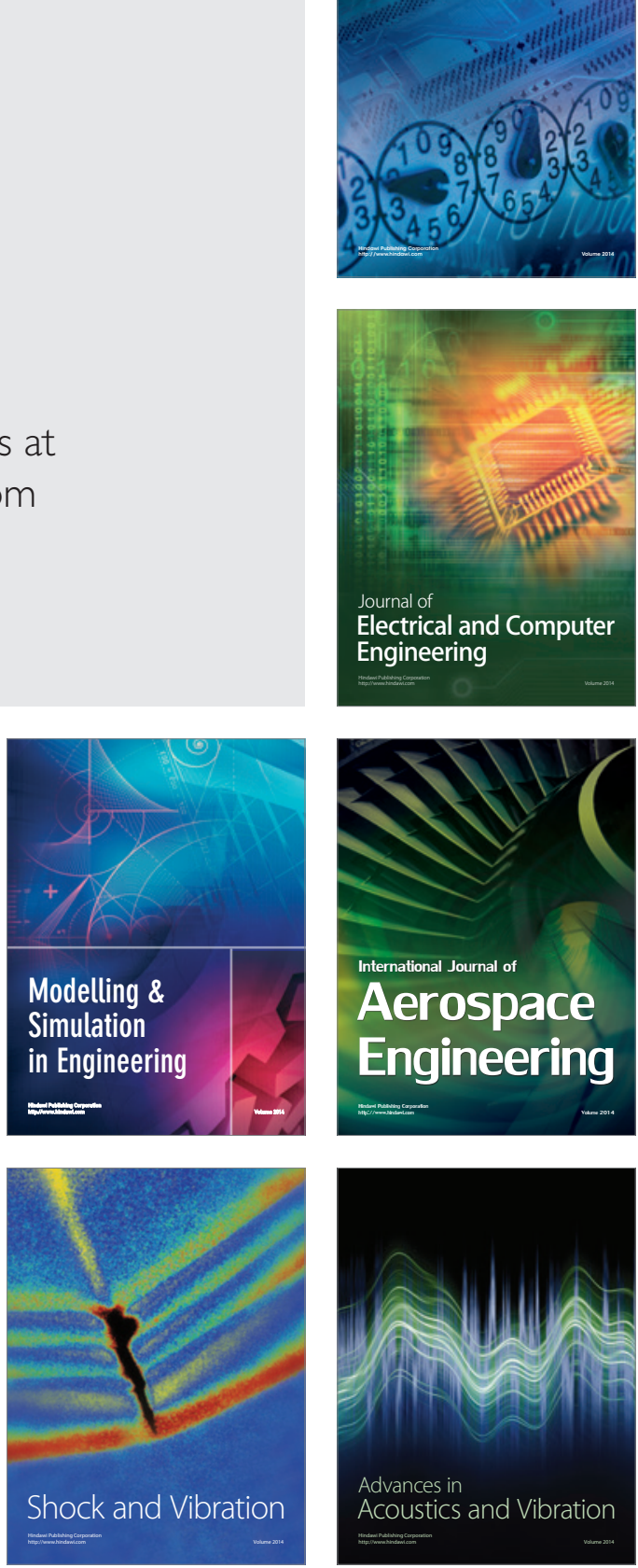